\title{
مقاربة مقاصدية لشعيرة الصوم في إطار فلسفة الدين
}

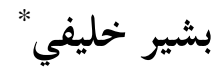

$$
\begin{aligned}
& \text { الملخص } \\
& \text { يُعَدُّ هذا البحث مقدمة أولية لمقاربة شعيرة الصوم وأخلاقه في الإسلام مقاصدياً، عن طريق محاولة التعمُّق } \\
& \text { في جملة المبررات العقلية للأهداف الحسية والروحية التي تتحقق بالصوم، ضمن إطار فلسفة الدين، مع الاعتراف }
\end{aligned}
$$

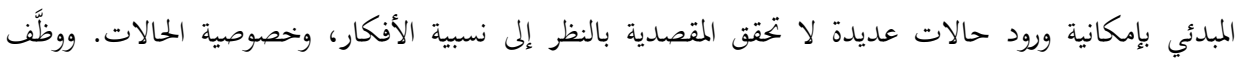

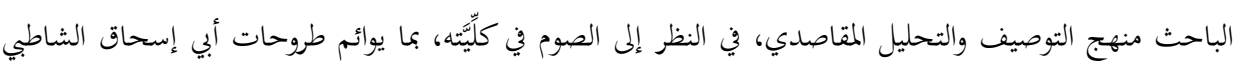

$$
\begin{aligned}
& \text { الذي جعل المقاصد أصل الأصول، بتجسيده قيمة الإحسان في جلب المصالح ودرء المفاسد على مستوى الدين، } \\
& \text { والنفس، والعقل، والمال، والنسل. وينفتح هذا المنهج على مقاربة متعددة التوجهات والتخصصات، ولا سيما تلك التي } \\
& \text { تُؤطرّها منظومة فلسفة الدين. } \\
& \text { الكلمات المفتاحية: الصوم، فلسفة الدين، قراءة مقاصدية، علاقة الروح والجسد، مرتبة التقوى }
\end{aligned}
$$

\section{A Maqasidi approach to the ritual of fasting within the framework of the philosophy of religion}

\section{Bachir Khlaifi}

\begin{abstract}
This research is a preliminary introduction to approach fasting as worship act within its own ethics according to the normative purposes and intents of Islam. It is an attempt to have a deep investigation of the rational purposes of the sensual and spiritual objectives of fasting, within a framework of philosophy of Religion. It assumes an initial recognition of the possibility of cases were fasting does not achieve the normative maqasid. The researcher employed a descriptive-analytical methodology, in looking at fasting in its entirety, in accordance with the ideas of al-Shatbi, who made the purposes the basic foundation of the religion, which requires the value of Ihsan in bringing benefits and preventing harms in preserving the five maqasid: religion, life, intellect, property and procreation. This methodology is open up to a multi-disciplinary approach that employs various interrelated disciplines, especially those framed by the philosophy of religion.
\end{abstract}

Keywords: Fasting- Philosophy of religion- Maqasidi approach, Spirit-Body relationship, Rank of Taqwa

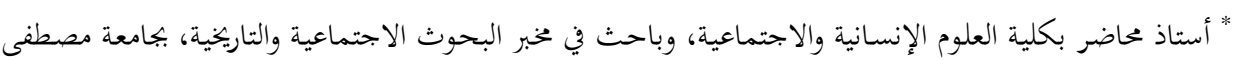

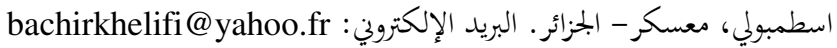

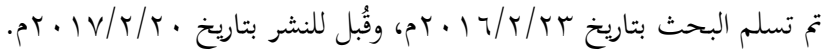




\section{مقدمة:}

يتفرَّد الإنسـان بميزة التسـاؤل والتفكير، فهو الكائن الوحيـد الذي يعقل وعيـه، بمـا

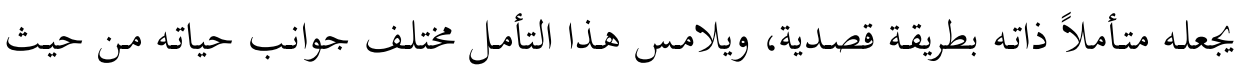

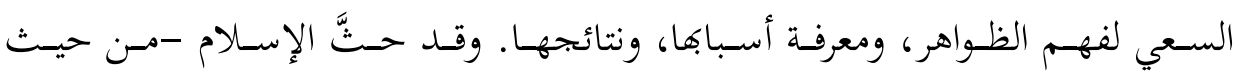

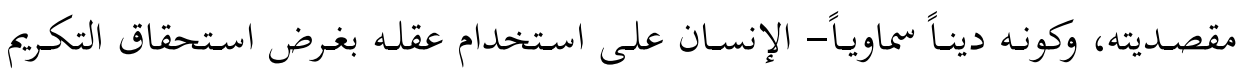
الإلهي، ثم الخلافة على الأرض للنهوض بحاله وأحواله، خصوصا وأنَّ العقل في مبدئه ومن حيث تسميته عقلاً، فهو يعقل أي يحبس ويمنع صاحبه عن التورّط في المهالك. في إحالة إلى أداة العلم والمعرفـة والتمييز ومَلَكَة الإدراك التي تمـنح الإنسـان الفـرادة والتميُّز وأهليـة الاستخلاف.

لقد فضَّل الله الإنسان وكرَّمه بعقله ليكون قَميناً بتحمُّل المسؤولية المقرونة بحريته، من

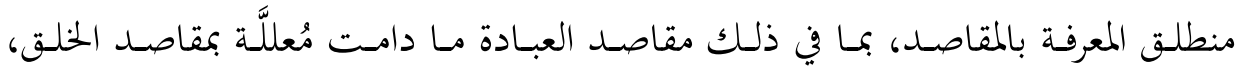

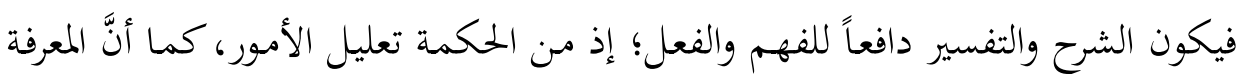

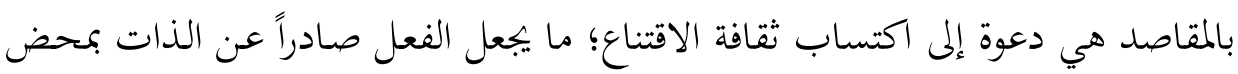

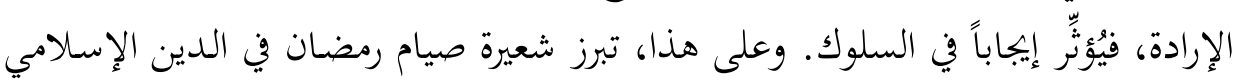

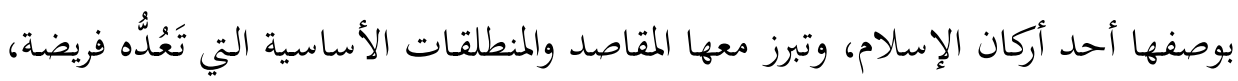

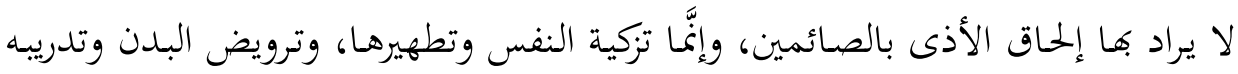

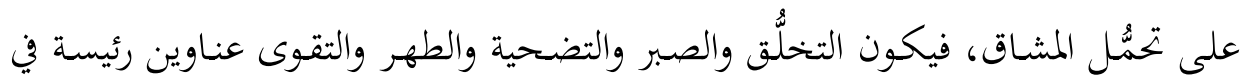

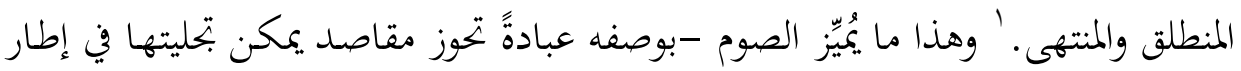

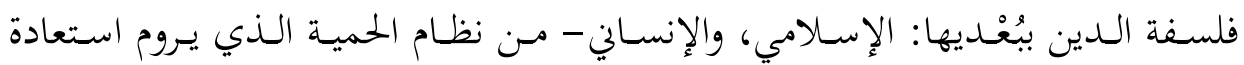
الرشـاقة، أو التوقـف عـن تنـاول الطعـام في أثنــاء الإضـراب عنـه، ليكـون الفــارق مرتبطـاً بالمقاصد والغايات.

وغايـة المقاربـة المقاصـدية تتأسَّسس على مراعـاة المقاصـد والغايـات واستحضـارها في

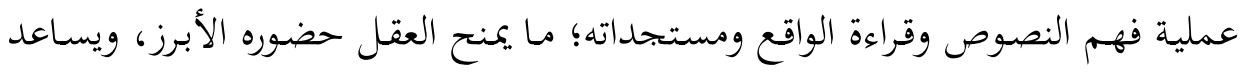




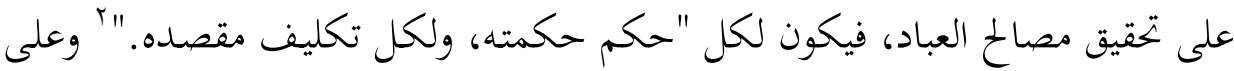

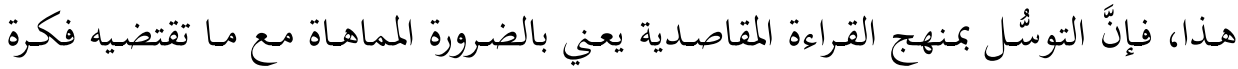

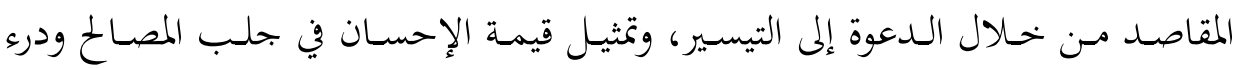

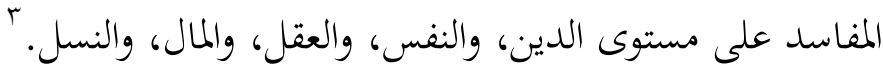
ولا شكَّ في أنَّ الوسيلة المهمة الأولى لكل قراءة مقاصدية تحيل بالضرورة إلى المعرفة

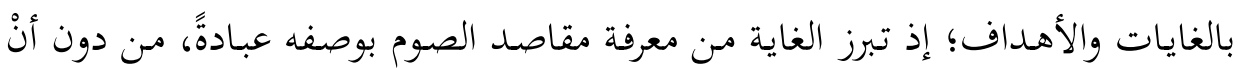

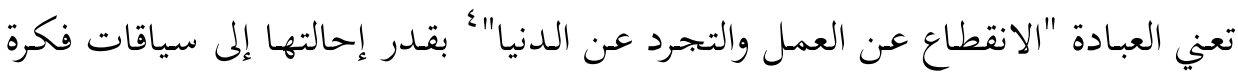

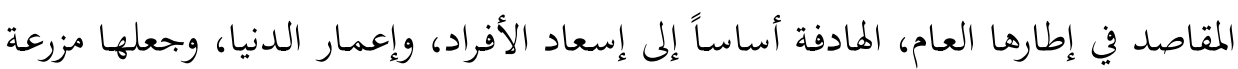
للآخرة بالإيمان والعمل الصالح.

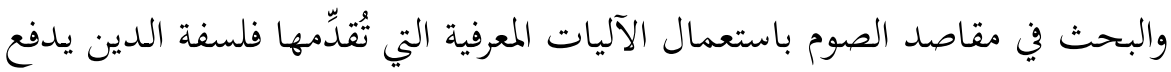

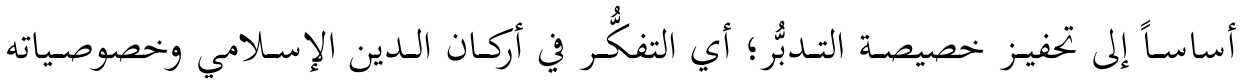

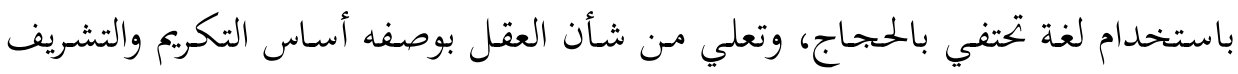

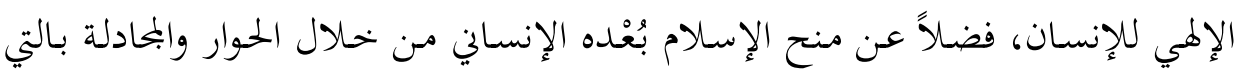

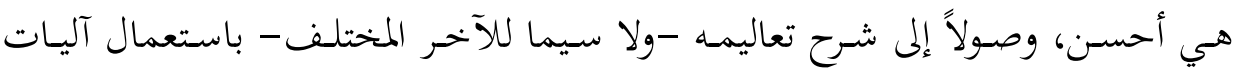

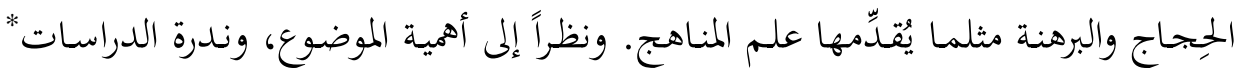

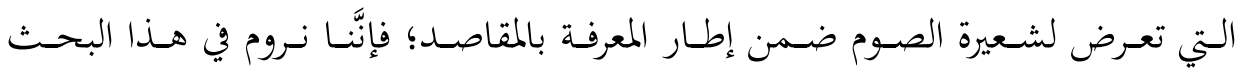

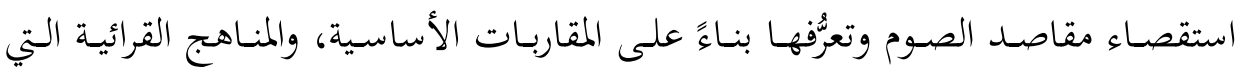
تُعَدِّمها فلسفة الدين في بُعْديها: الإسلامي، والإنساني.

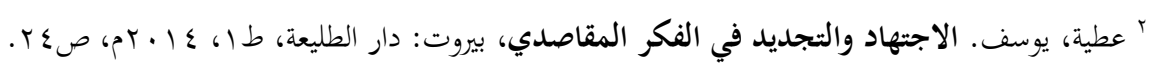

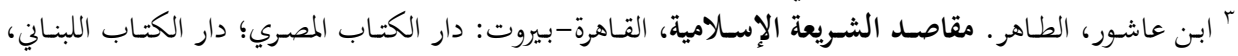
V. V.

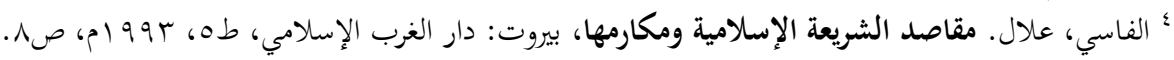

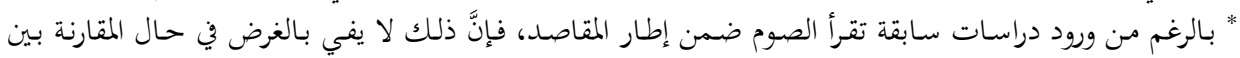

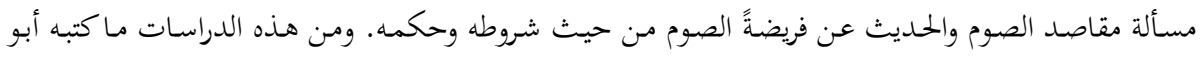

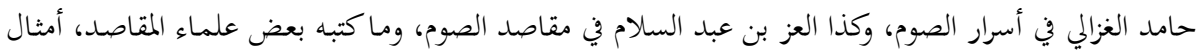
الطاهر بن عاشور، وأحمد الريسوني. 
أولاً: فلسفة الدين؛ المفهوم والمقاصد

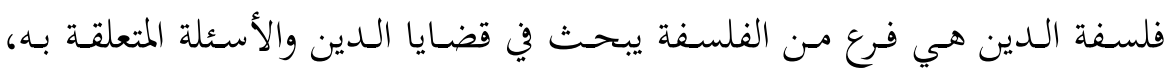

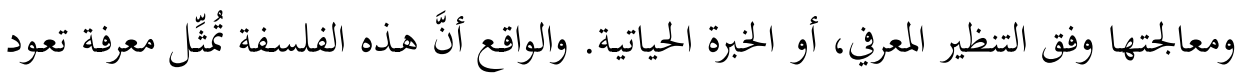

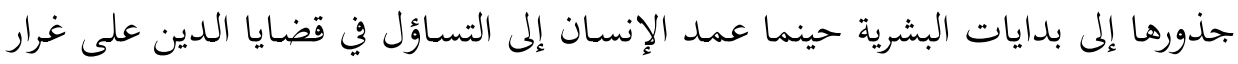

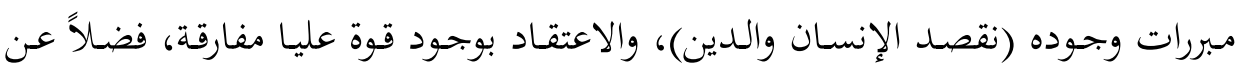

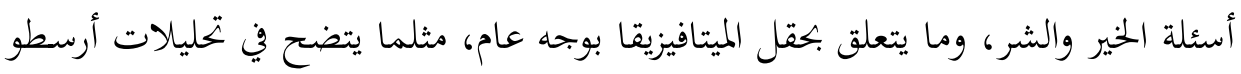
الذي حاول تحليل العالم عن طريق الذات الإلهية، أو المرك الذي لامبل لا يتحرك. فميلاد فلسفة الدين فرضته الحاجة المعرفية الملحة للفهم، ثم استكناه مختلف آليات

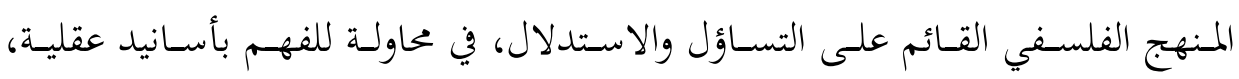
استناداً إلى المحاولات المحادة للإجابة عن الأسئلة التي يطرحها الدين. وقد ارتبط التصور العام لفلسفة الدين بمعالجتين أساسيتين، تحيل إحداهما إلى النزعة

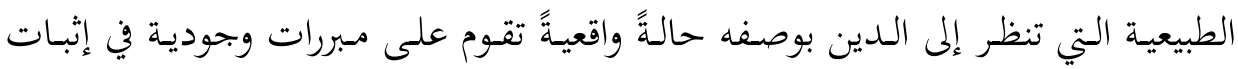

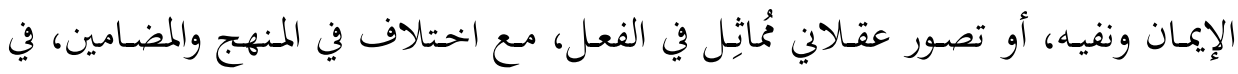

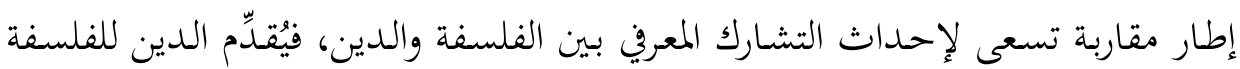

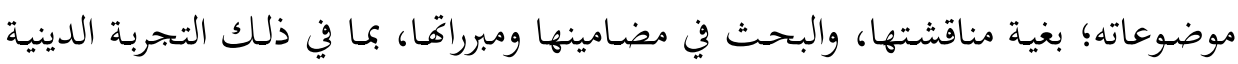

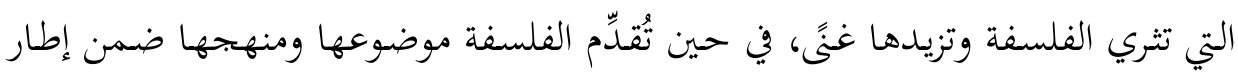

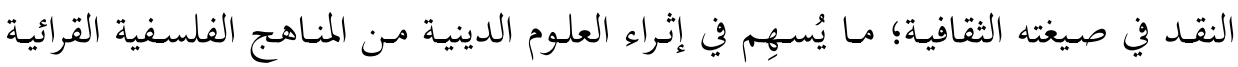

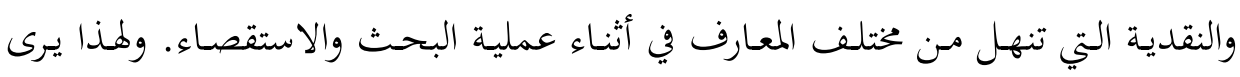

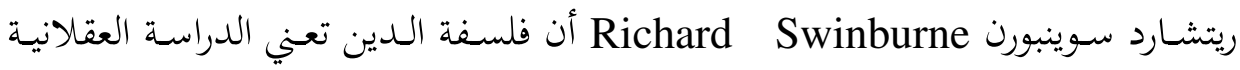

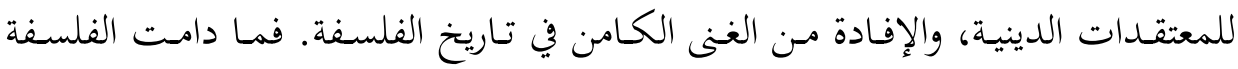

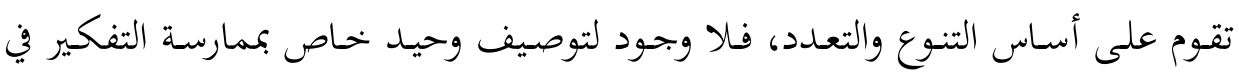

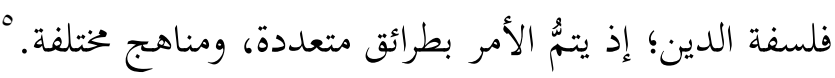

${ }^{5}$ Phillips, DZ and Tessin, Timothy. Philosophy of Religion in the 21 century, New York: Pealgrave Macmith Edition, 2001, Introduction, P 3. 
وفي إطـار فلسـفة الـدين هـذه، فقـــ انبثقـت العديـــ مـن الـرؤى التحليليـة والنقديـة

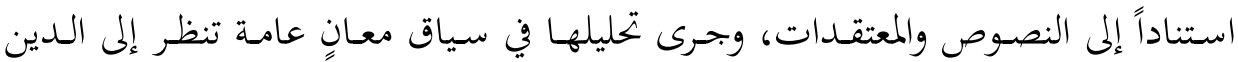

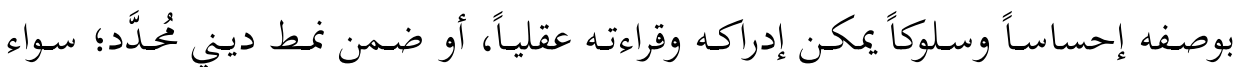
بالبحث التفصيلي في فلسفة الدين محل الاعتقاد، أو بالمقارنة بين دين وآخر . وهذا يُمثِّل

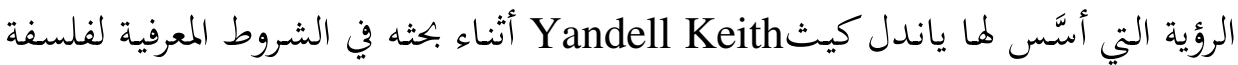

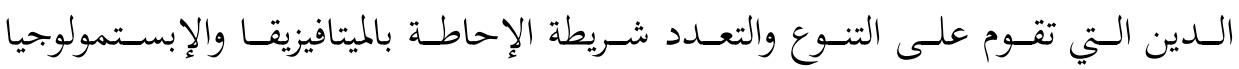

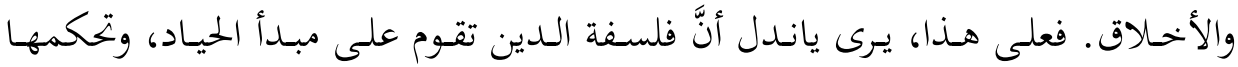

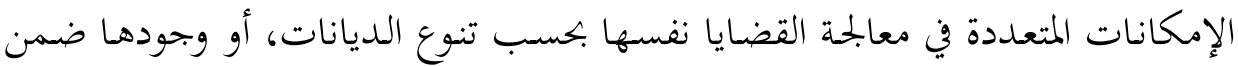
دائرة الإيمان وخارجها؛ ما يجعل الحالة الفردية والإحساس عنصرين مهمين لفهم الظاهرة الدينية.

\section{ثانياً: سؤال الصوم في إطار فلسفة الدين}

يحيل الصوم لغةً إلى الإمساك والكف، مثل قولنا: "صام عن الكالام" بمعنى توقف.

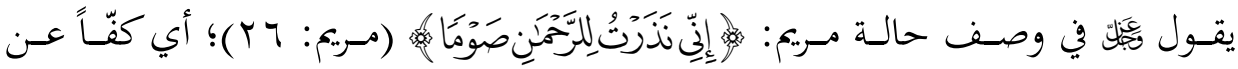
الكاملام.

أمَّا في إطار الممارسة الدينية الإسـلامية فإِنَّ الصوم يُعبِّر عن ركن رئيس مـن أركان

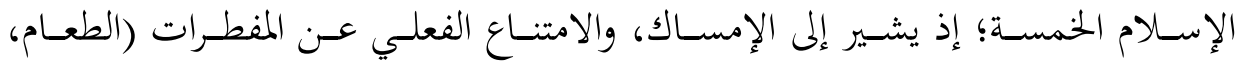

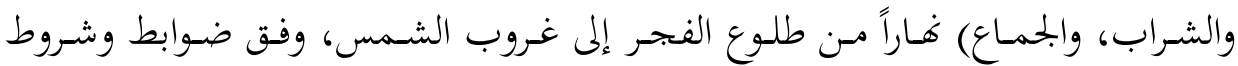

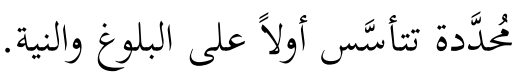

وعلى هذا، فالصوم يُحتِّم الامتناع والإمساك عن أشياء مخصوصة على وجه مخصوص

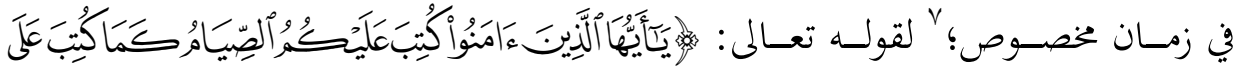

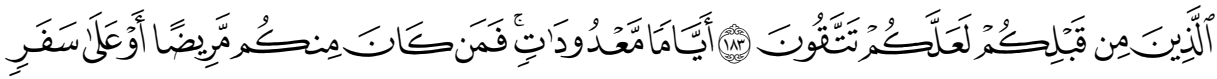

${ }^{6}$ Yandell, Keith. Philosophy of Religion, London and New York: A Contemporary Routledje, 1999, PP 14, 18. 


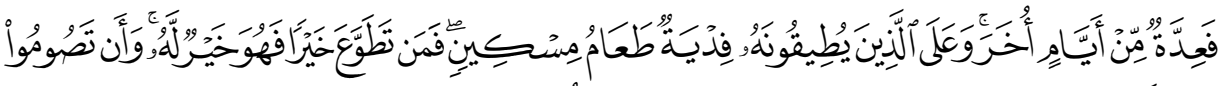

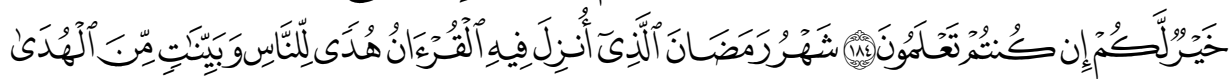

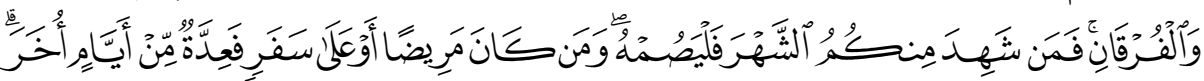

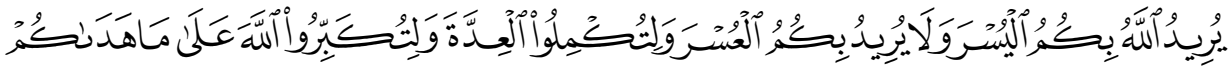

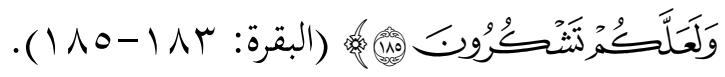

وينبغي الإقرار بـأنَّ الصوم يُمتّلّل ممارسة بشرية قديمة ارتبطت بـالكثير مـن الديانات

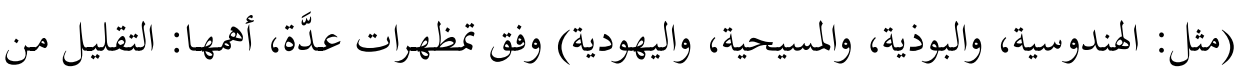

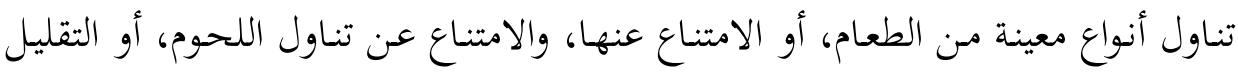

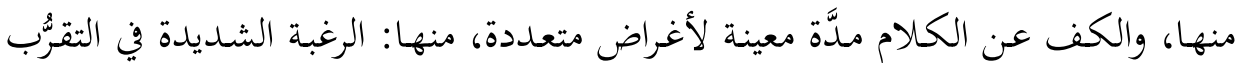

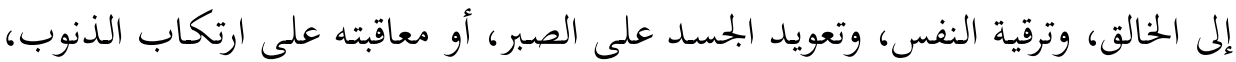

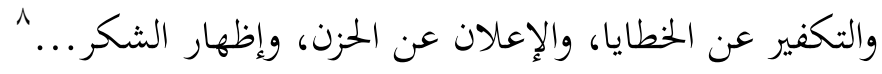
وبالمقابل، وضمن الإطار المعريف للصوم، يرى الكندي أنَّ الفلسفة هي معرفة الأشياء

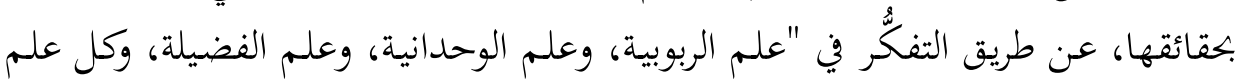

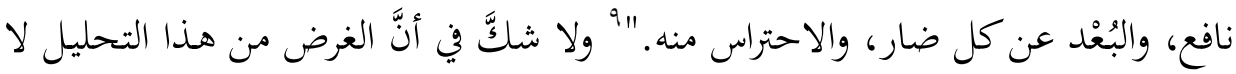

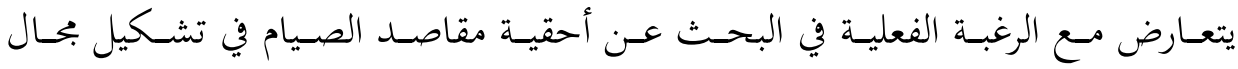

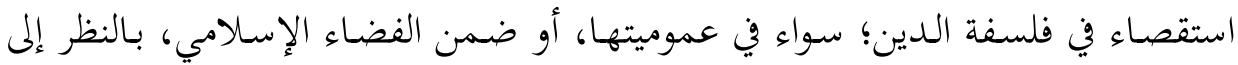

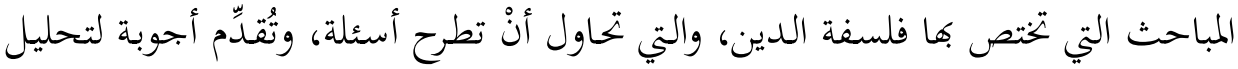

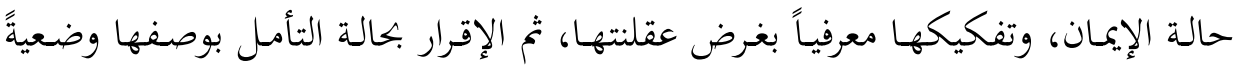

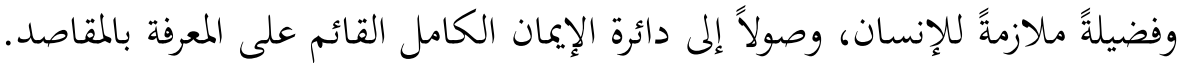

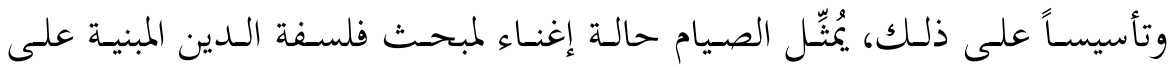

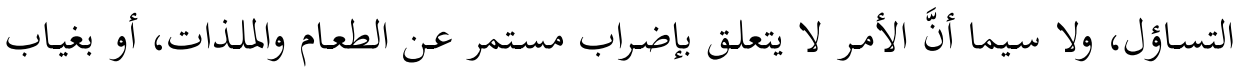
^ الموحي، عبدالرزاق رحيم صلال. العبادات في الأديان السماوية، دمشق: الأوائل للنشر والتوزيع، طا، ا... بم، صابـ 1. 9 الكندي، يعقوب بن إسحاق. كتاب الكندي إلى المعتصم بالله في الفلسفة الأولى، نقلاً عن:

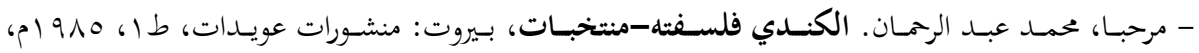


تام للطعام بقدر مـا يجيل إلى استجابة إرادية لفرض إلهي وواجـب ديني مقرون بمنظومة

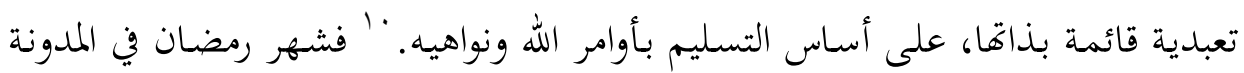

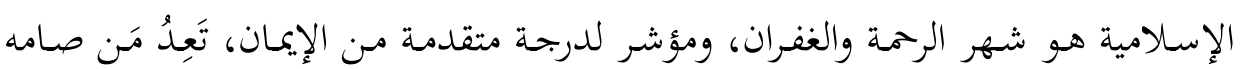
على أحسن وجه بالمغفرة والطمأنينة والخحير العميم.

وما دامت فلسفة الدين ترنو في إطارها العام إلى استقصاء المفاهيم الدينية وتفعيلها بغيـة تحصسيل مقصــ الاقتنـاع المفضي إلى السعادة؛ بتحقيق شـروطها على الصعيدين:

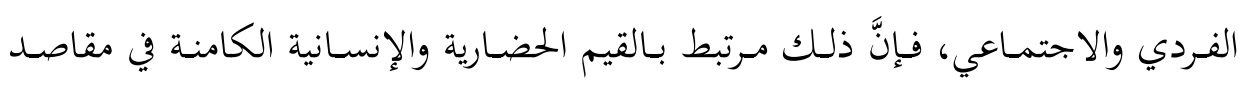

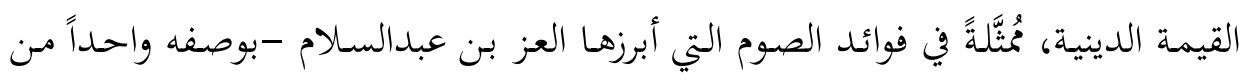

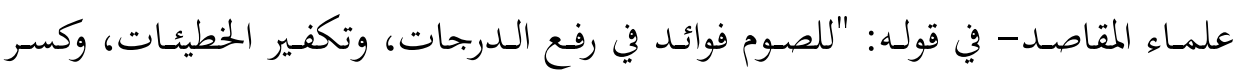

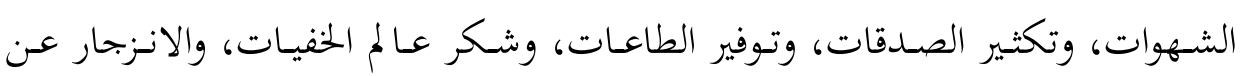

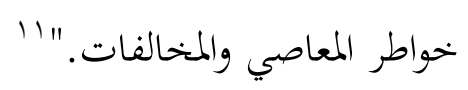

للذلك ستكون معالجـة هـذه المسـألة في مقـام أول ضـمن إطـارين مُتمَـاهيين: يتعلق

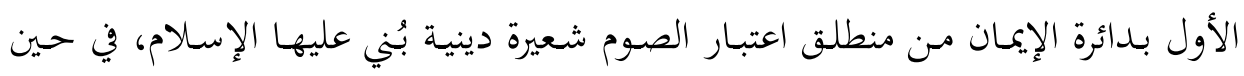

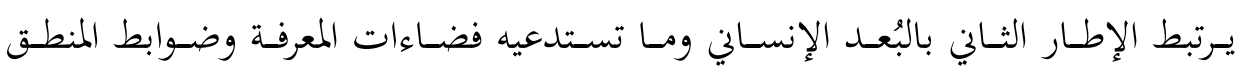

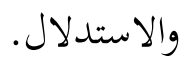

\section{ثالثاً: الصوم بين الإيمان والعقل}

يبرز أثر الصوم جلياً بوصفه حالةً مثبتةً للتمازج الحاصل بين العقل والوحي؛ إذ إنَّ

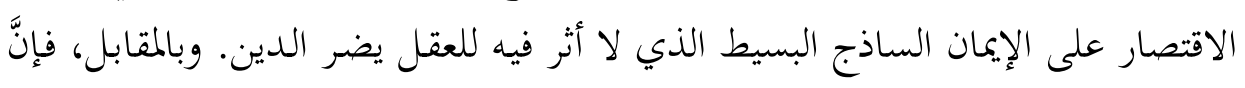

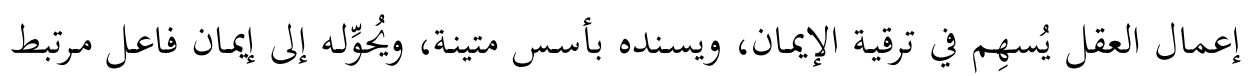

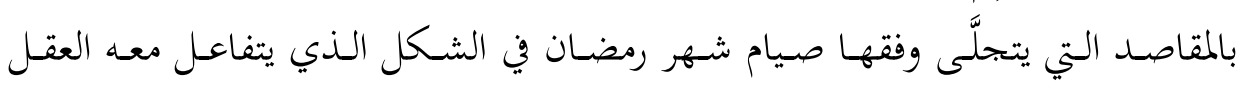

${ }^{10}$ Salamone, Frank. Encyclopedia Religious, Rites, Rules and Festivals, New York and London: Routledj, 2004, P 37.

" ابن عبد السلام، العز. . مقاصد الصوم، تحقيق: إياد خالد الطباع، بيروت-دمشق: دار الفكر المعاصر؛ دار الفكر، 
بالإيمان؛ إذ تتمثَّل أهميته في التفكير في مقاصده وفوائده المتعددة التي تُؤثّر إيماباً في حياة

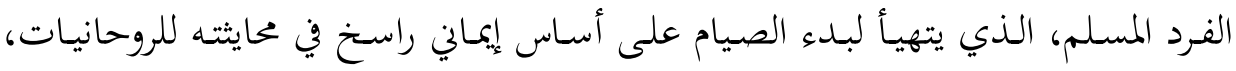

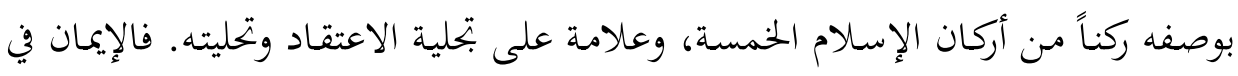

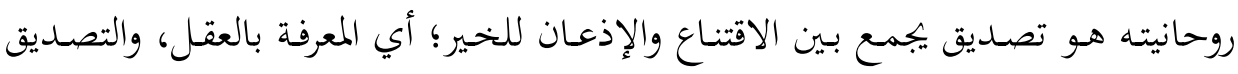
بالقلب، والإقرار باللسان، والعمل بالأركان.

وعلى هذا، فلا يراد مـن صوم رمضـان معاقبة النـاس، والحيلولة دون تمتعهم بمباهج

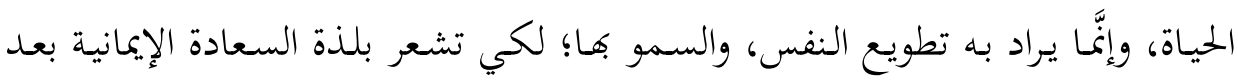

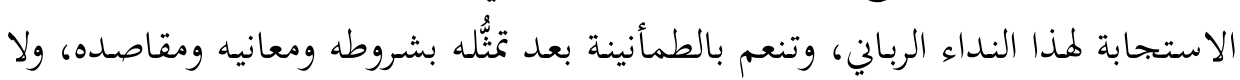

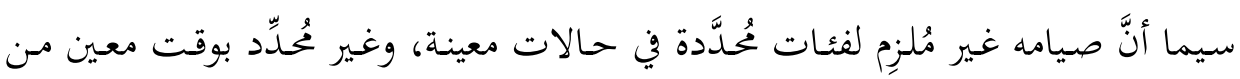

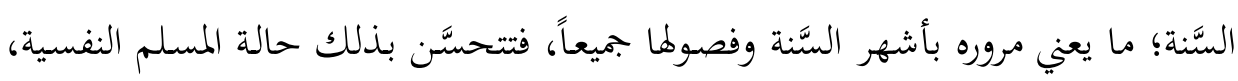
وتتهيأ للارتقاء.

ولا شــكَّ في أنَّ المقصـد الأسـاس للمسـلم في هـذا الشهر الفضـيل هـو نيـل مطلب

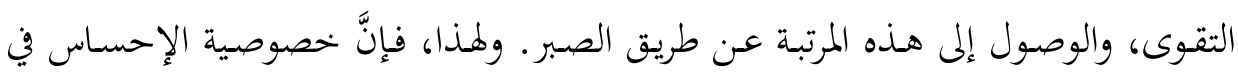

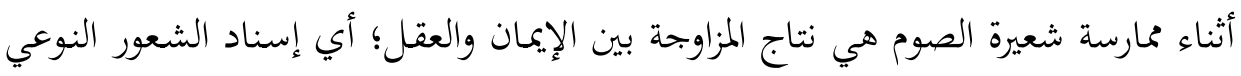

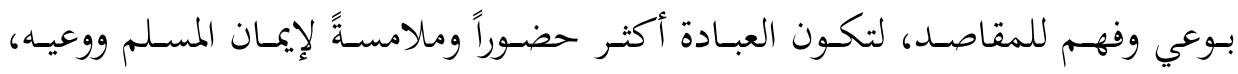

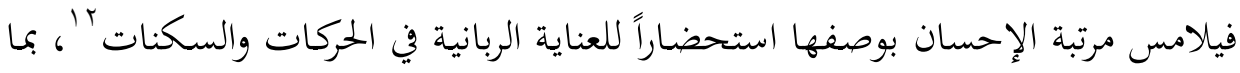

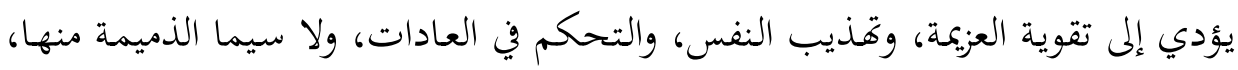

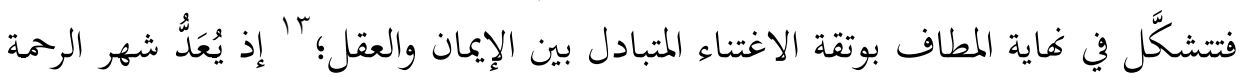

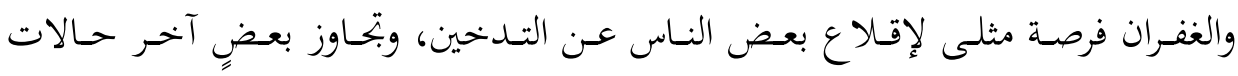

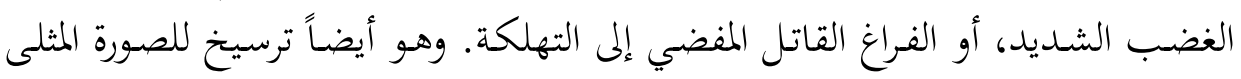

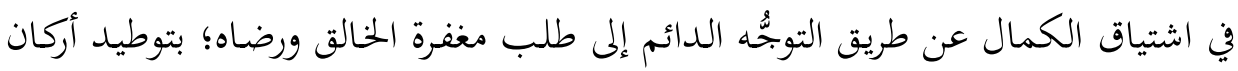

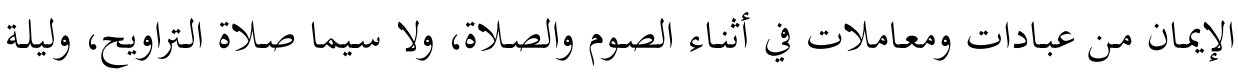
القدر التي هي خير من ألف شهر.

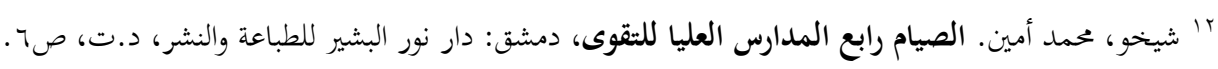

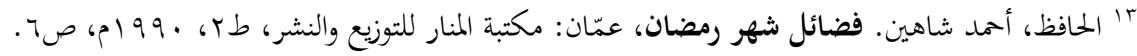




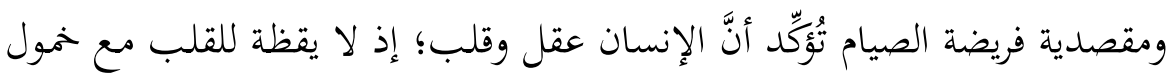

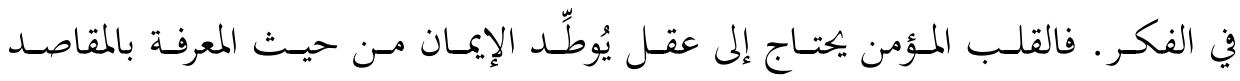

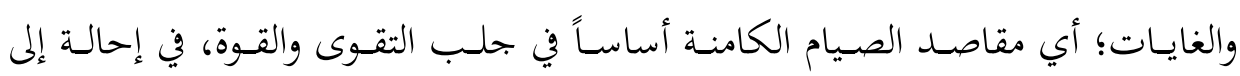

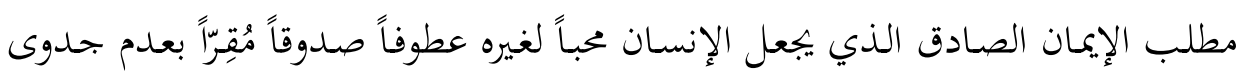

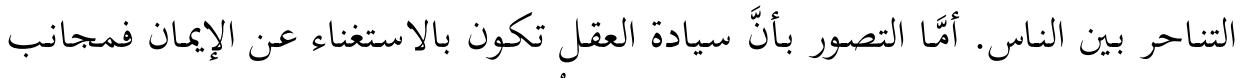

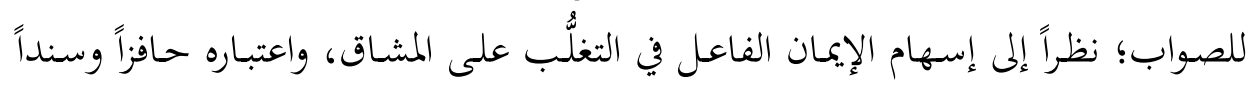

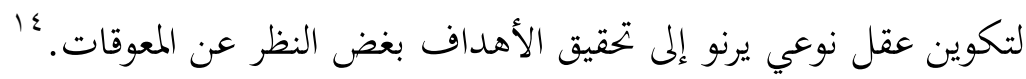

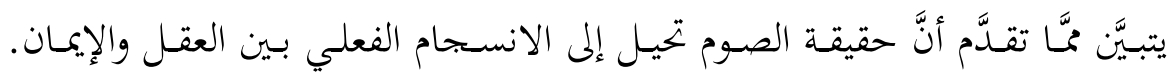

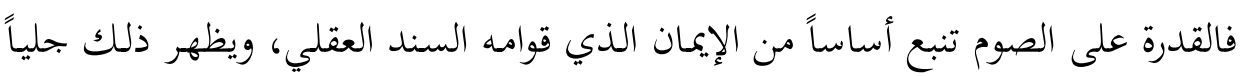

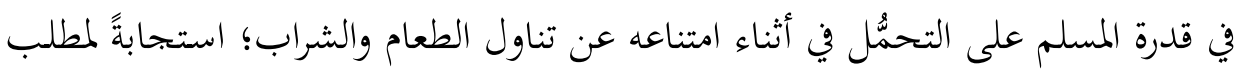

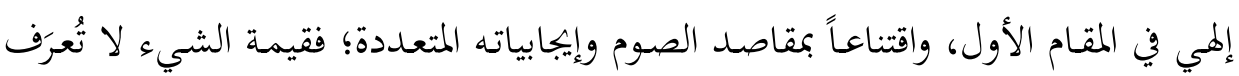
إلا بعد فقدانه، فيكون التوقف عن تناول الطعام والشراب وبقية المفطرات الحلال وسيلة

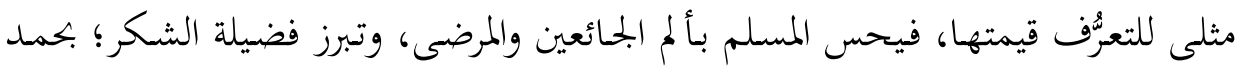

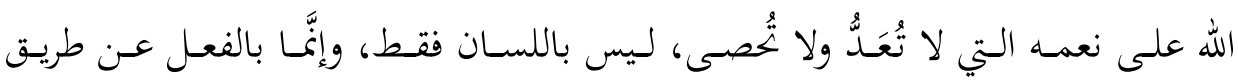

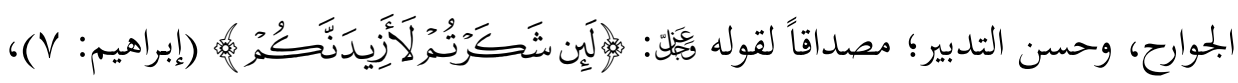

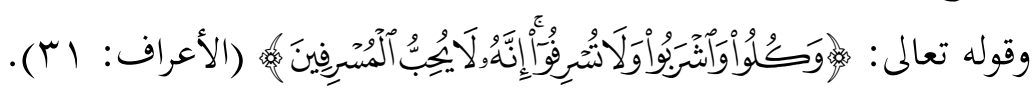

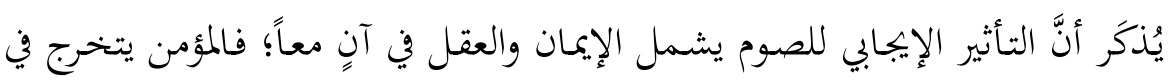

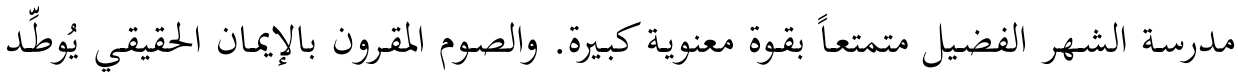
علاقة الإنسان بخالقه وبالناس، ويمد العقل بتيار ديني مُعبِّر عن الفطرة السليمة، فيجعله

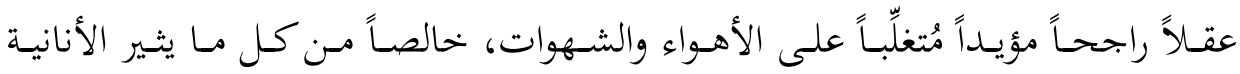
والشحناء والكراهية. 10

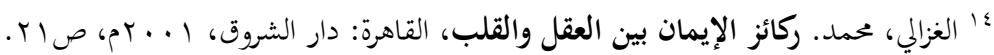

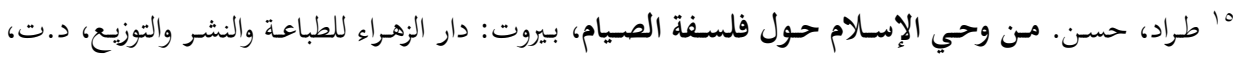




\section{رابعاً: الصوم بين المادة والروح}

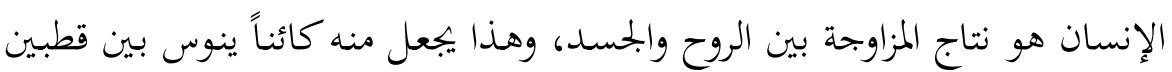

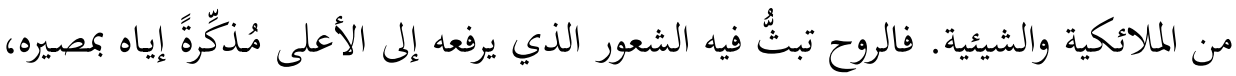

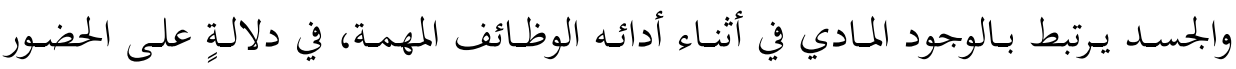

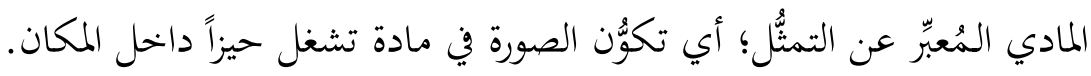

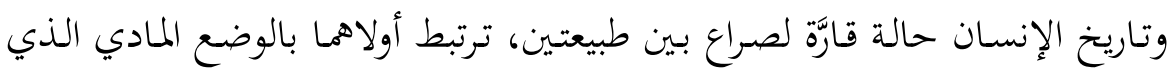

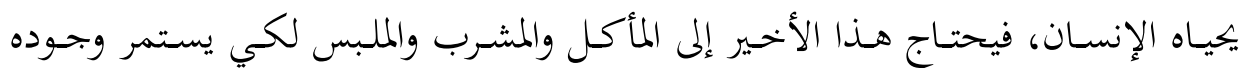

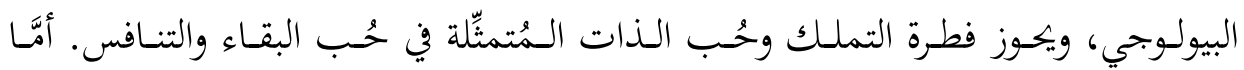

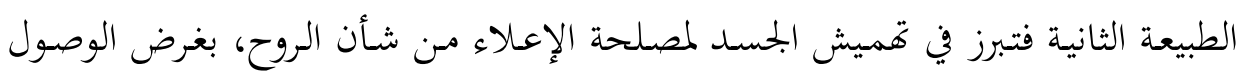

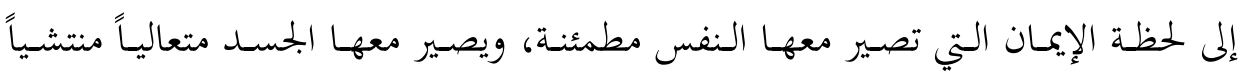

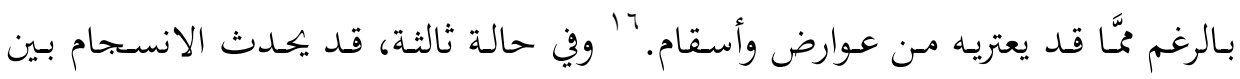

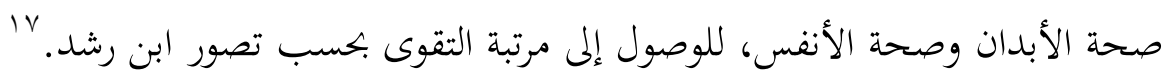

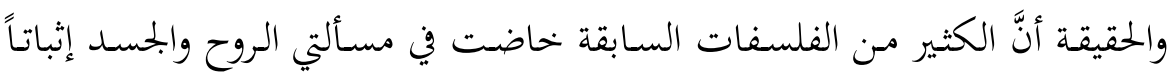

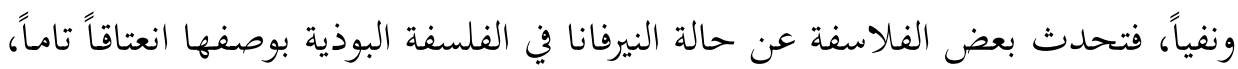

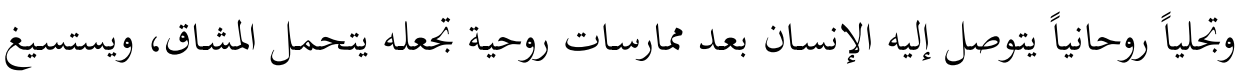

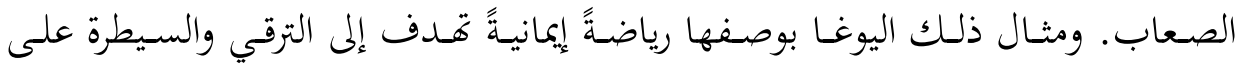

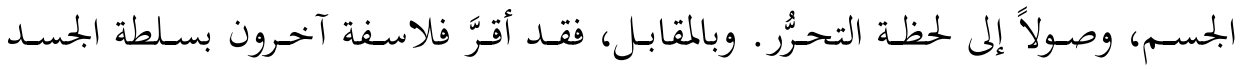

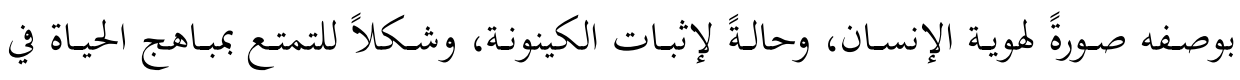

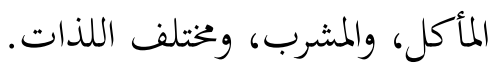

وفي هذا الإطار، تبرز خصوصية الصيام في إحداثه الانستحام والتناغم بين الحياة

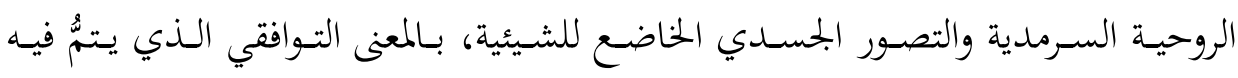

${ }^{16}$ Sethi, Mohini and Jain, Barkha. Fasting and Feasting, New Delhi: New Age International Publishers, 2000, P ^r.

"l ابن رشد، أبو الوليد. فصل المقال فيما بين الحكمة والشريعة من الاتصال، دراسة وتحقيق: محمد عمارة،

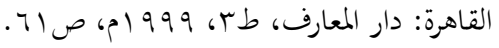




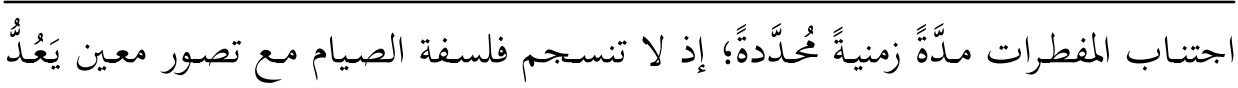
الجسـد سبباً للسيئات، ومصدراً للشرور، مـن منطلق حمله الغريزة المفضية إلى الانحراف.

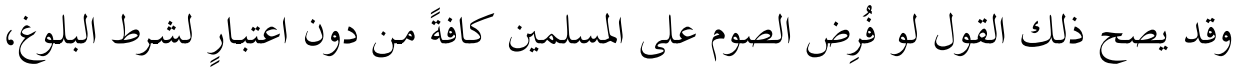

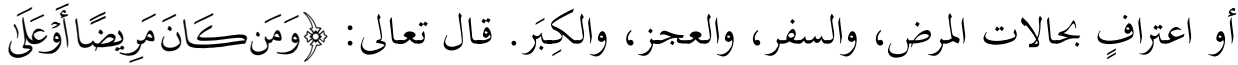

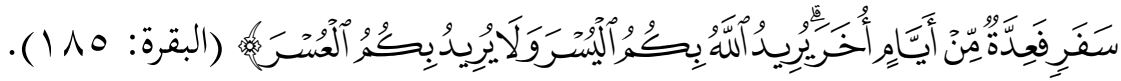
وتشريع صوم رمضان ومقصديته يحيلان إلى اعتباره مدرسةً تجعل المتخرج فيها أَهْلاً

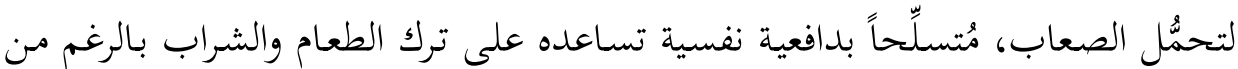
توافرهما، فيشعر بلذة الصبر المنبعثة من الطاقة الروحية في الإحاطة بفضائل شهر رمضان؛ شهر الرحمة والغفران، فترتاح المعدة، وتصفو النفس، وتشرق الروح، وهو الانسجام الذي عبَّر عنه رسول الله والصيام جُجنَّة، وإذا كان يوم صوم أحدكم فلا يرفث ولا يصخب، وإنْ سابَّه أحد أو قاتله فليقل إنِّ امرؤ صائم. والذي نفس محمد بيده لخلوف فم الصائم أطيب عند الله من ريح

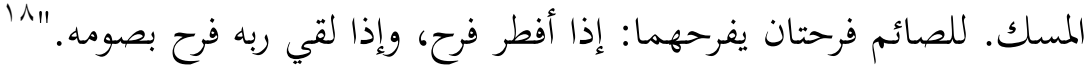
ففي هذا الحديث يتعالى الجسد في اتصاله بالروح، فيُعبّر الإفطار عن الفرحة بكسر

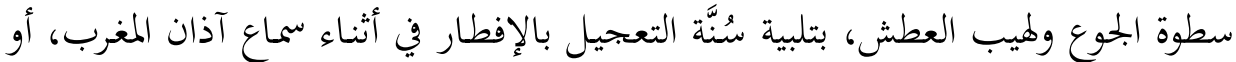

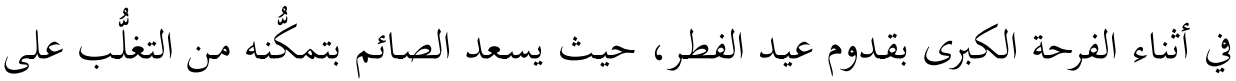

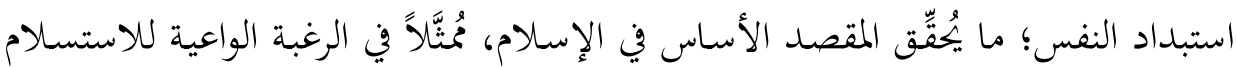
للخالق لَّيَلْ من حيث المعرفة بمقاصد العبادات.

ولا شكََّ في أنَّ هذا الفهم يُوَسِّس لتصور أخلاقي للجسد، من حيث تأكيد أسبقية

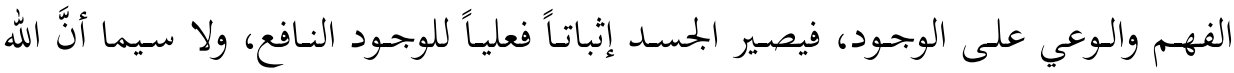

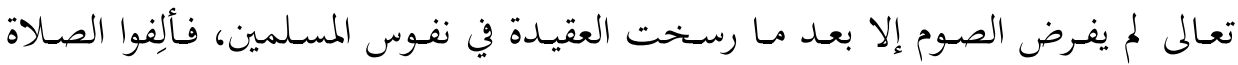

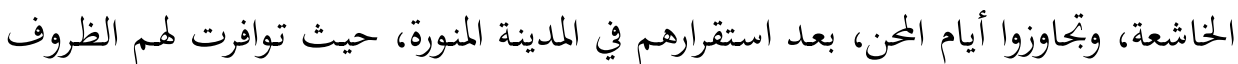

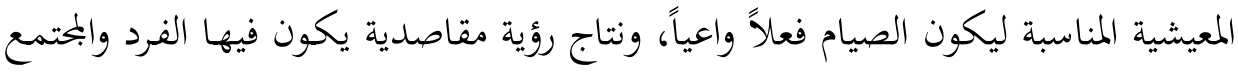

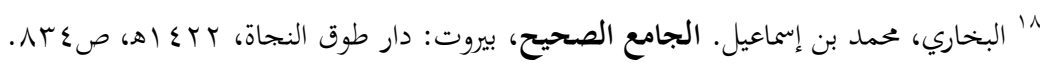


مُنتِجاً تُحقِّقاً للتطور والاستقلالية في معانيها المختلفة، بمنأى عن الحاجة والاضطرار؛ لأنَّه لم يُفرَض أساساً في أجواء من الجوع والمسنبة.

وفلسفة الصيام في الإسلام تقوم على مقصدية الحفاظ على الجسد؛ فالمسلم القوي

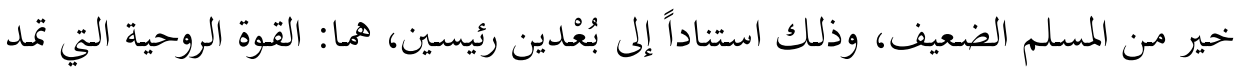

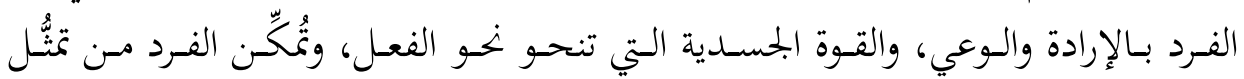

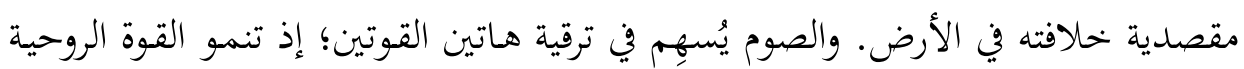

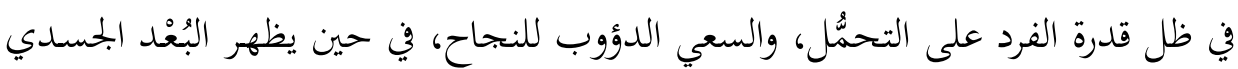

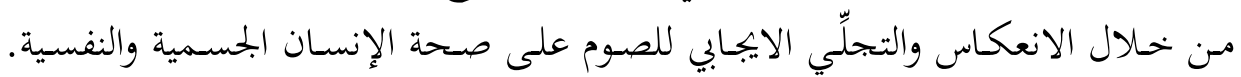

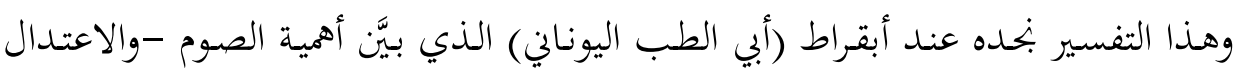

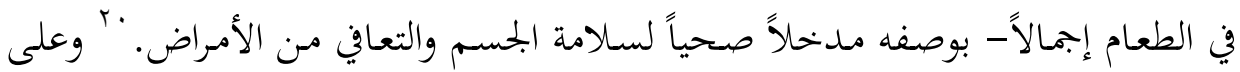

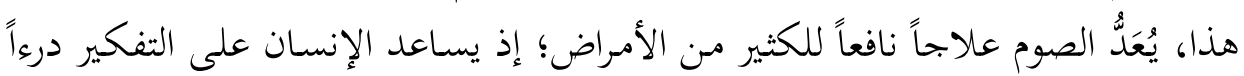

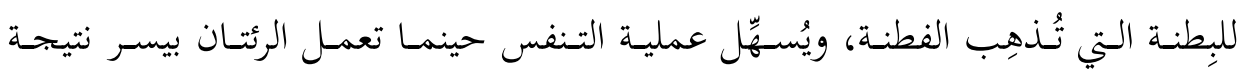

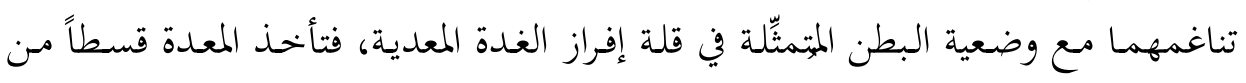

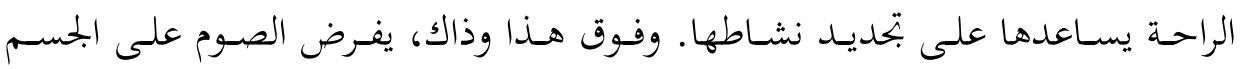

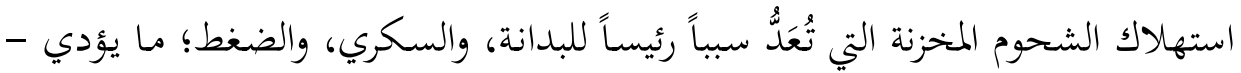

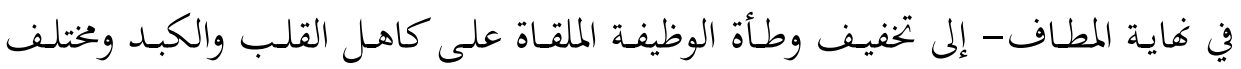

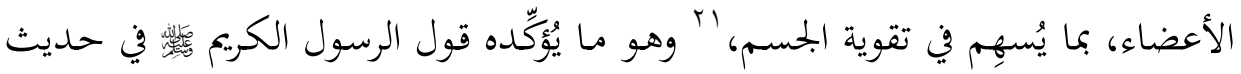

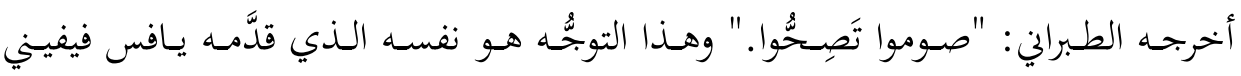
حينمـا عقـــ في كتابـه عـن الصـيام مقاربـة بـين الإمسـاك عـن الطعـام

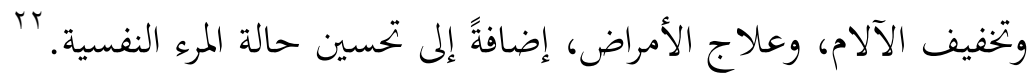

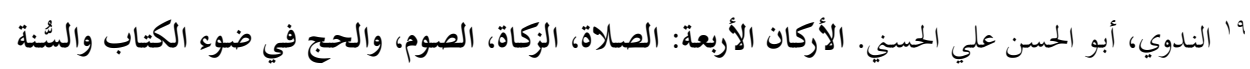

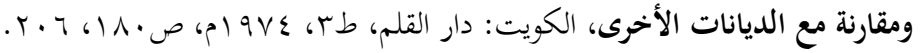

${ }^{20}$ Laty, Dominique. Les Regimes Alimentaires, Paris: Que sias je, Press Universitaire de France 1996, P 16.

${ }^{21}$ Dave, William. The Miracle Results of Fasting: Discover the Amazing Benefits, in your Spirit, USA: Souland Body, Marrison House, Tulse Oklahoma inc, 1984, P 37.

${ }^{22}$ Vivini, Yves. Le Jeune et les Traitements Naturelles, Toulouse, France: Les Presses de L'imprimerie du Sud, 1970, P 9. 


\section{خامساً: مدرسة رمضان وتشكيل الإنسان النوعي}

شهر رمضـان هـو بحق مدرسة متميزة لتشكيل الإنسـان النوعي؛ إذ يسـاعده على

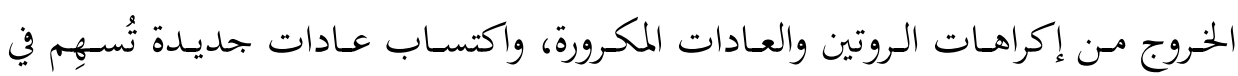

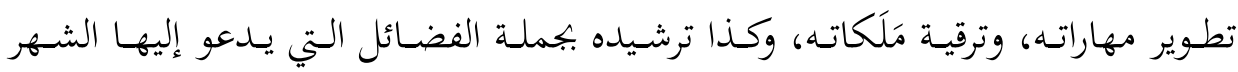

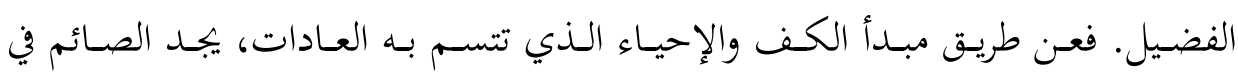

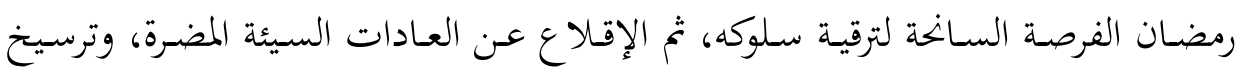

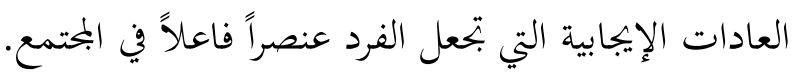

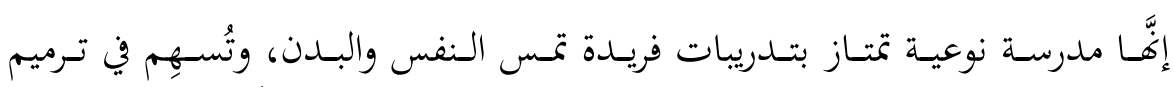

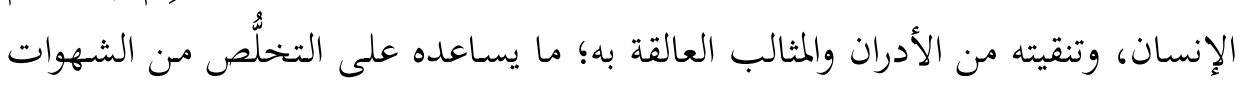

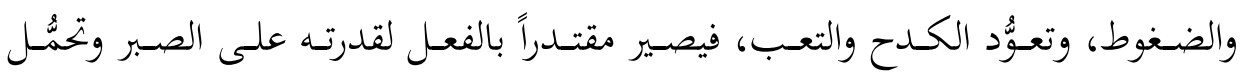

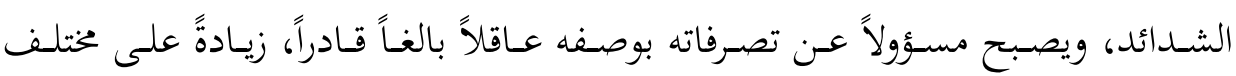

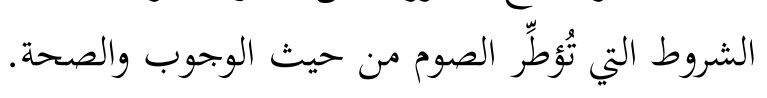

وفي السـياق نفسـه، تقـوم فلسـفة الصسيام في جزئهـا اليَنَغِيَـاتي خاصـةً على التـآزر

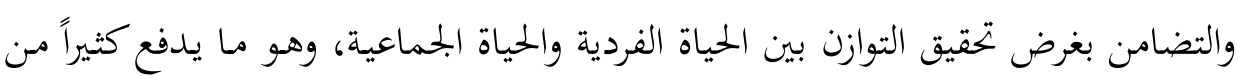
الأفراد والمحتمعات إلى الاستعداد له والاحتفال به، عن طريق إحيائه بالعبادات والأنشطة

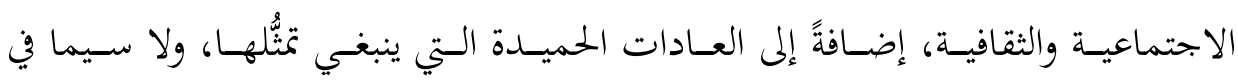
الفعاليات والممارسات التي تضطلع بها الجحاليات المسلمة في بلاد المهجر، بما يُعرَف بموائد الإفطار الجماعية، ومسن ذلك أنشطة أفراد الجالية المسلمة في القطب المتجمـد الشمالي

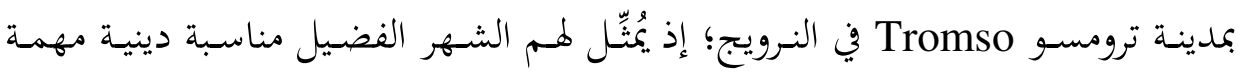

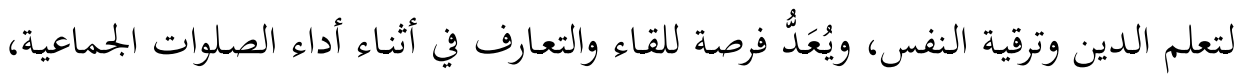

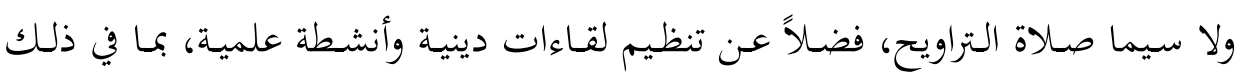

$$
\text { الاجتماع على موائد الإفطار الجماعية. }
$$

${ }^{23}$ Yunis, Alia. Ramadan in the Farthest North, KSA: In, Saudi Aramco World Magazine, Vol63, January/ Febrary 2012, P 25. 


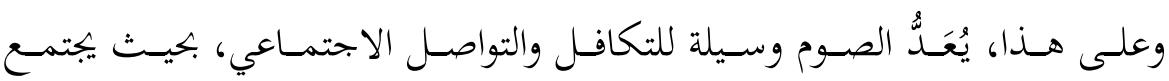

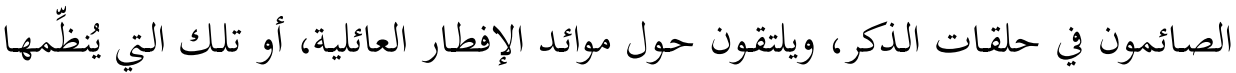
المحسنون من الخواص والجمعيات الخيرية بغرض إطعام المسافرين والفقراء وعابري السبيل.

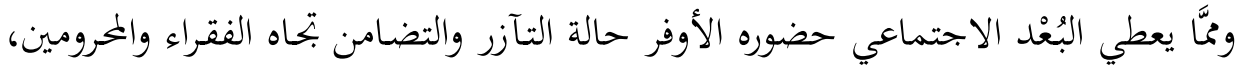

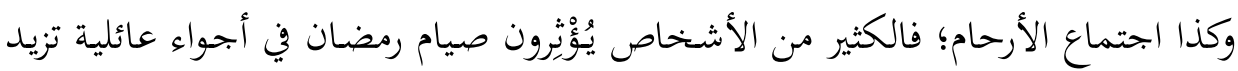
من لحمة الأسرة وتماسكها.

ويمتاز شهر رمضان عن غيره مـن الشهور بتوطيــ وشـائج المحبة والتـآلف بـين أفرد

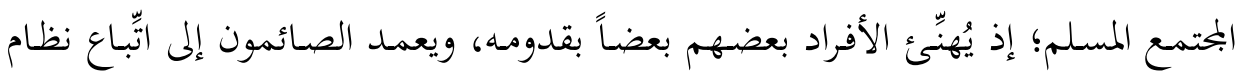

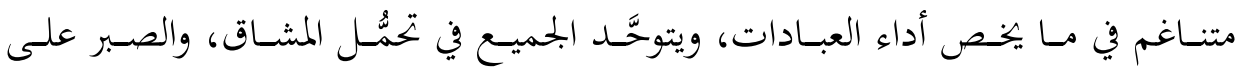

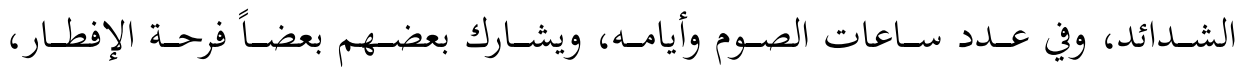

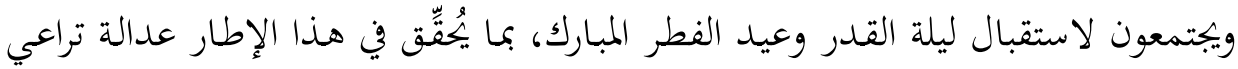

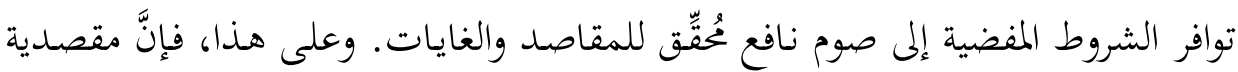

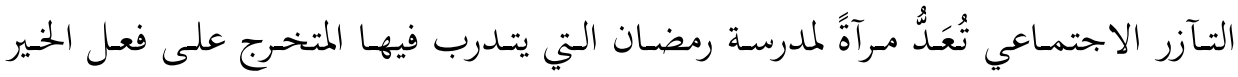

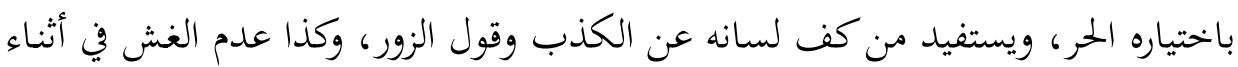

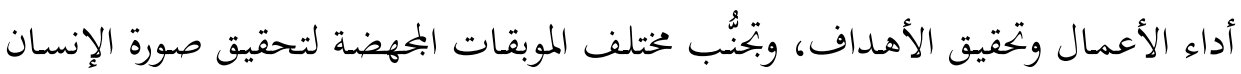
الحضاري.

وبـذلك يتجـه الفـرد نحو توطيد الخـبرة الدينيـة في جوانب حياته المتعددة، ولا سيما

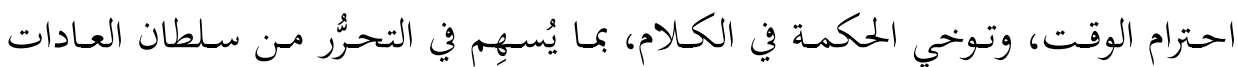

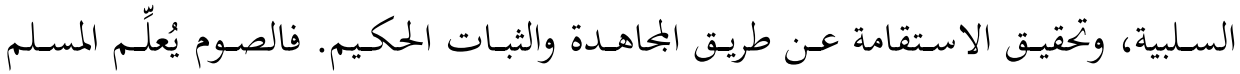

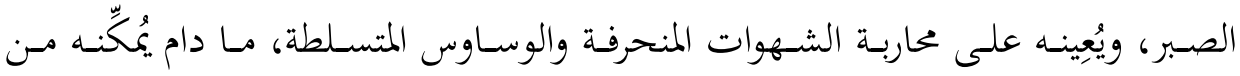

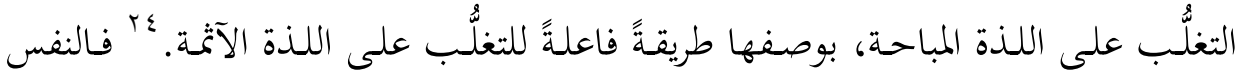

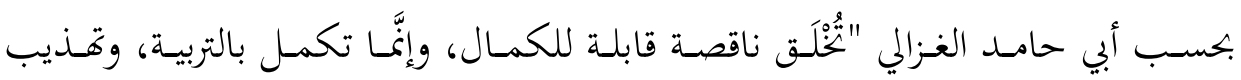

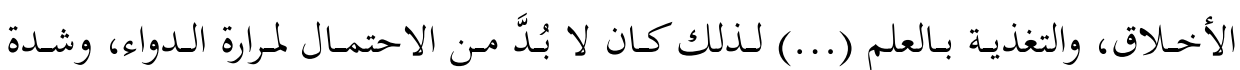

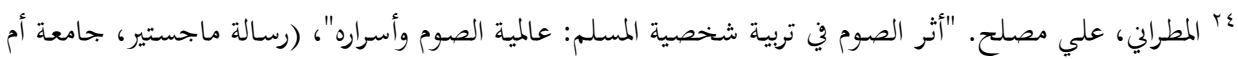

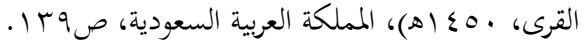


الصبر على المشتهيات لعلاج الأبدان المريضة، فكذلك لا بُدَّ من احتمال مرارة المحاهدة والصبر لمداواة مرض القلب. ro" re

والواقع أنَّ تشكيل الإنسان النوعي مرتبط بسعيه للتحلي بالإيمان الموصل إلى مرتبة الإحسان، حيث تتجلى الاستقامة الفردية في أبهى صورها؛ إذ يعمد المسلم طوال أيام

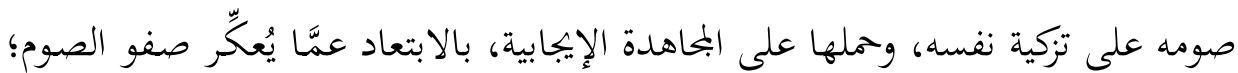

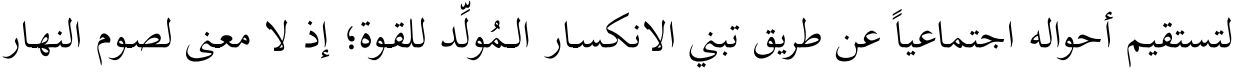
تم الإفطار بالحرام، ولا معنى لكسر شهوة الطعام ثم تعويضها بالنهم والشره عند الإفطار، ولا معنى أيضاً لإكثار النوم في النهار من دون الإحساس بالعطش والجوع ومعاناة المرضى

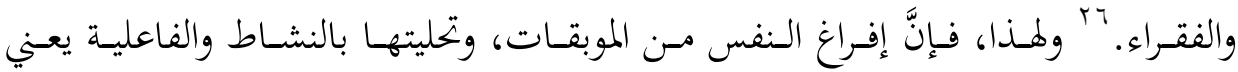

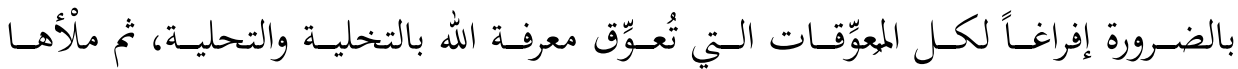

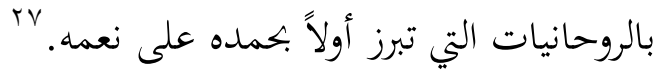

وقد لخَّص أبو حامد الغزالي فلسفة الصوم بقوله: "اعلم أنَّ الصوم ثناث درجات:

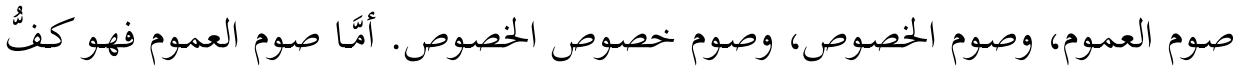

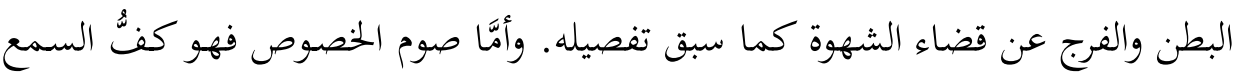

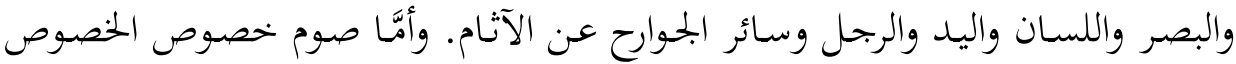

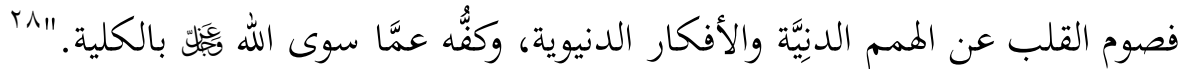

\section{سادساً: مدرسة رمضان وسؤال الزمن}

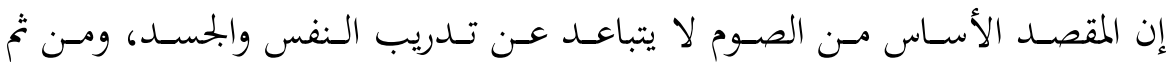

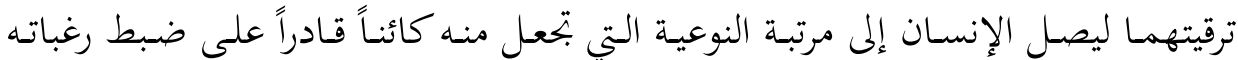

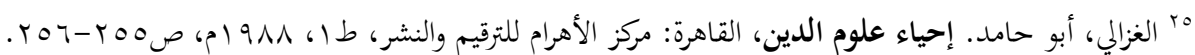

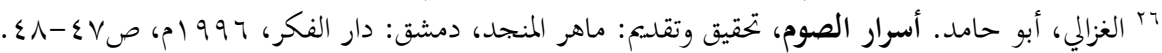

27 Towns, Elmer. Knowing God Through Fasting, USA: Destiny Image Incp, Shippensburg, 2002, P 12.

$$
\text { ^^^ الغزالي، أسرار الصوم، مرجع سابق، ص• ع. }
$$




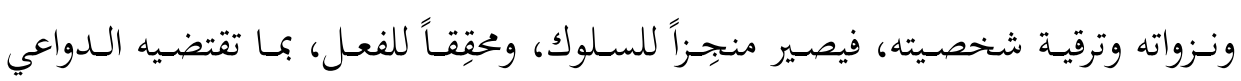

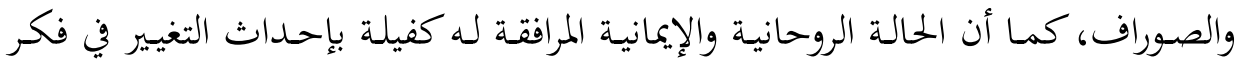
الإنسان وسلوكه نحو الأحسن، شريطة ارتباط ذلك بوعي عميق مُدرك لمقصدية الصوم،

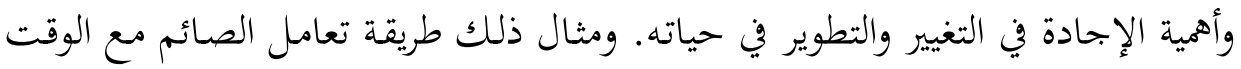

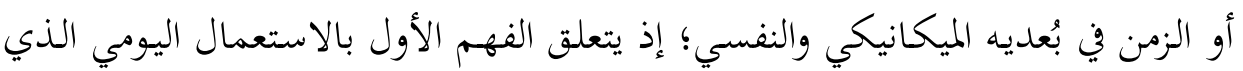

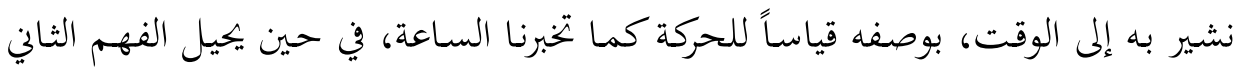

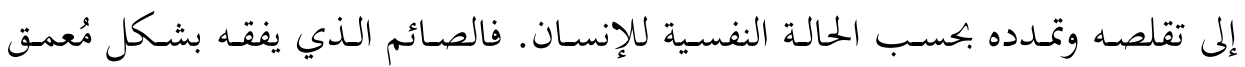

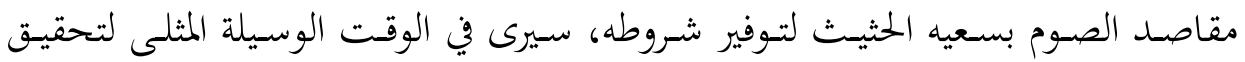
الغايات والأهداف، سواءُ بالإحالة للزمن الدنيوي في سمته المؤقتة، أو في إحالته للأبدية لِّية والسرمدية من حيث ارتباطه بالآخرة بوصفها دار الخلود.

الحديث عن الزمن بوصفه مساراً يومياً مزامناً لحياة الفرد، لا يعرف التتمة والانقضاء

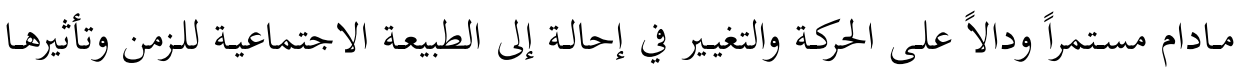

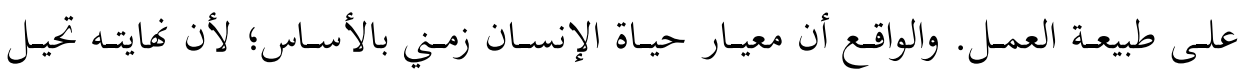
بالضرورة إلى فاية حياة الفرد. لذلك يتحدد الزمن من خهالال تصورين أساسيين: تصور

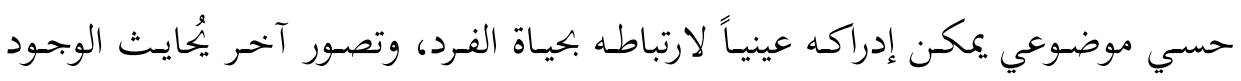

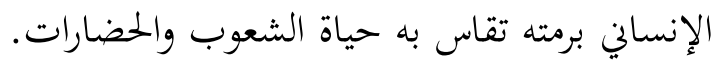

ضـمن هـذا الإطـار تـبرز علاقـة الصـوم بـالزمن، سـواء مـن حيـث موعـد الإمسـاك والإفطار، أو حينما يتعلق الأمر بشهر رمضان المبارك بوصفه موعداً سنوياً يتم تحديده

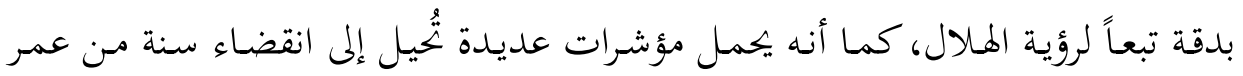

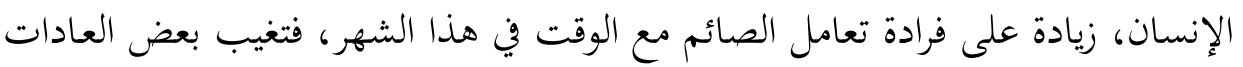

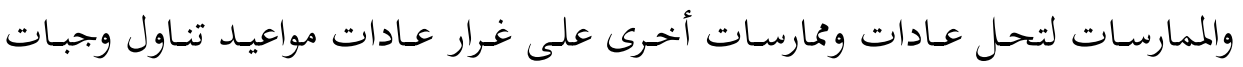
الطعام. إن التفرد في إدراك الصائم لعامل الوقت، سواء في إجرائيته؛ لأنه المحدد لبداية الصوم وهايته، أو في أبعاده ومقاصده المختلفة، سيفضي -لا محالة- إلى جعل الوقت التحدي 
الأبرز؛ الأمر الذي يدفع إلى استغلاله بما يحقق القيمة والفائدة بوصفه قيمة مضافة

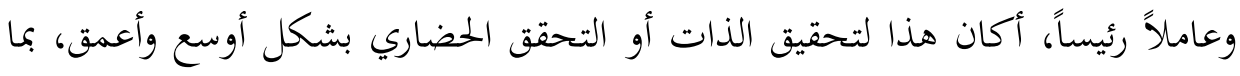

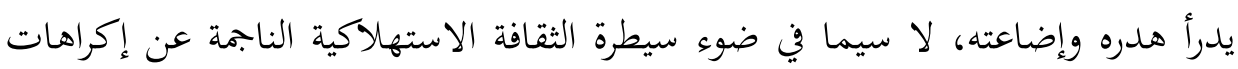

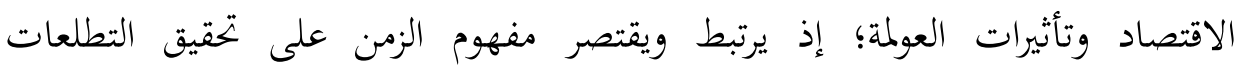

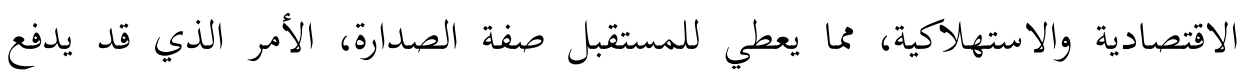
الإنسان إلى الكدح وفق المقاربة الاقتصادية، فيصير كل ما هو خارج عن تحقيق تطلعات الاتهيل

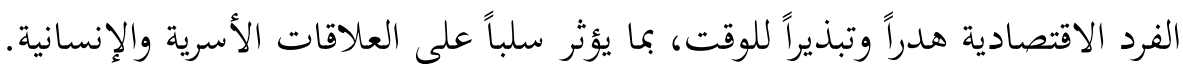
كما أن الالتزام الدائم والمطلق بسمة الزمن الأبدية والسرمدية، من حيث ارتباطه بالآخرة بوصفها دار الخلود، قد يفضي إلى فهم حِدِّي يعطي مبرر عدم الحاجة إلى بلى إلى

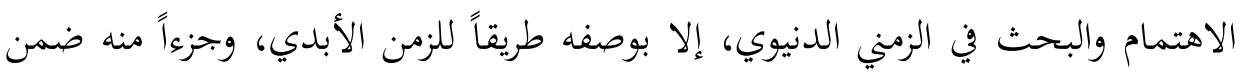

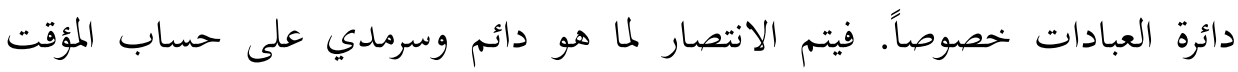

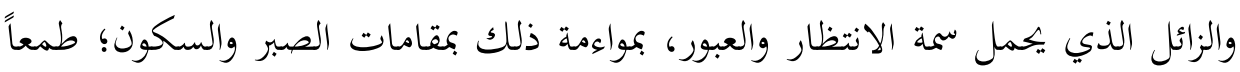
في النجاة، ومن تيّ الوصول إلى لحظة السرمدية والخلود، فيكون للزمن الأبدي تأثيره

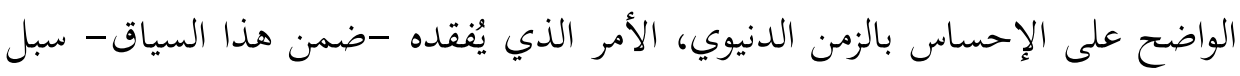

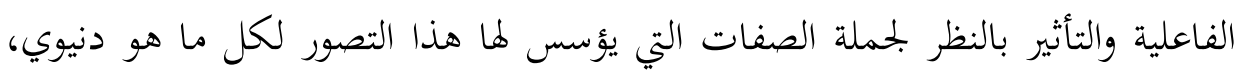

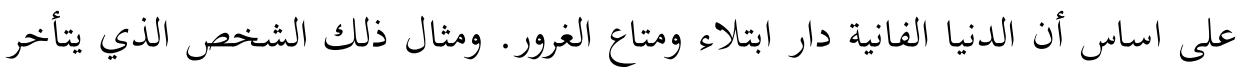
أو يتغيب عن العمل بكجة صومه واستغراقه في العبادة، علماً أن العمل عبادة أيضاً. ما من شك في أن الأداء الإيجابي والفعّال لشعيرة الصوم يُلزم الصائم بحسن التدبير

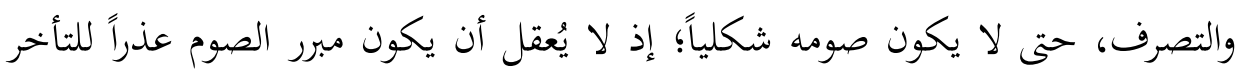

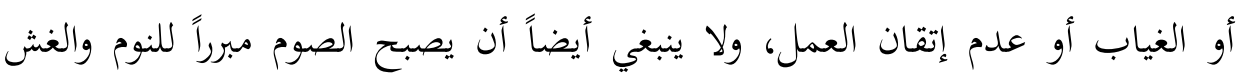

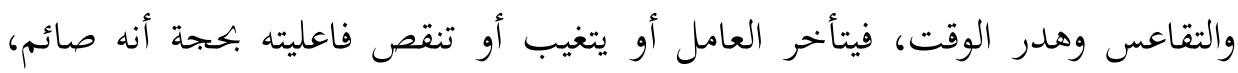

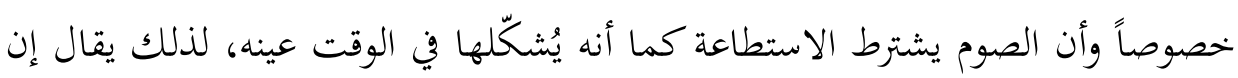

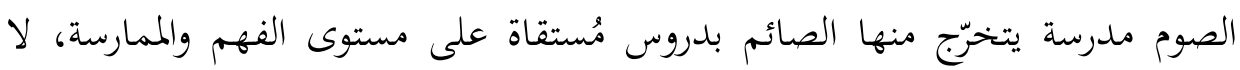

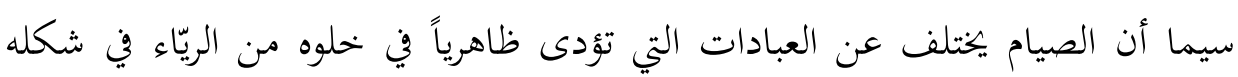


الفاضح؛ لأن منطلقه الأساس الكف عن المفطرات، وفيه يتساوى الصائمون في الكف

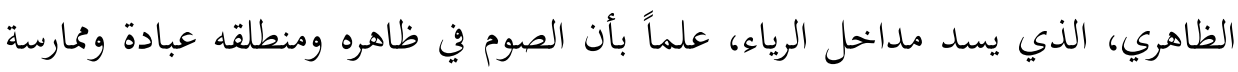

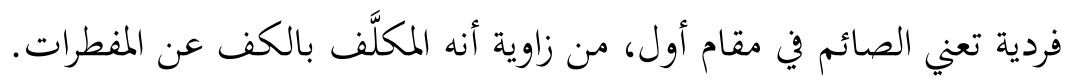
يُعدُّ صوم شهر رمضان مدرسة فعلية للإنسان؛ إذ يتكوّن ويتخرّج بقدرة على الصبر

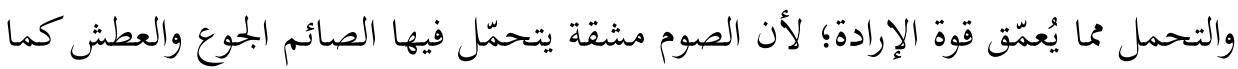
يقاوم الملذات والشهوات، الأمر الذي يُعلي من خصيصة الإحسان عنده؛ لأنس إندان الصائم رقيب نفسه من منطلق أن الصوم عبادة فردية بالأساس؛ إذ لا أحد يعلم إفطار الصائم

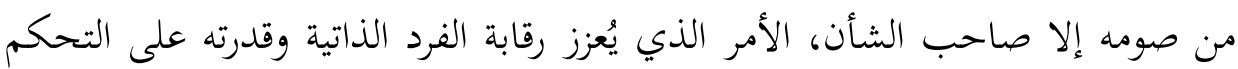
في نفسه. فيكون شهر الصوم قطيعة مع عديد العادات السيئة التي تستبد بالإنسان

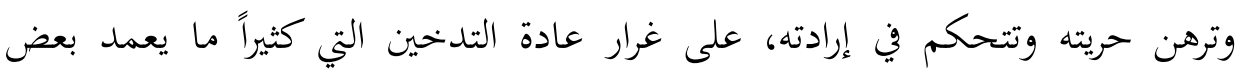
المدخنين إلى الاستفادة من شهر الصوم للإقلاع عنها فئه فئئاً.

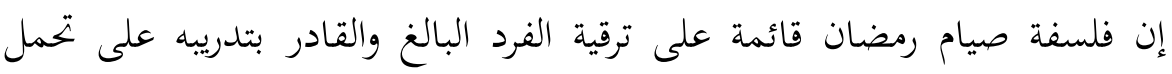

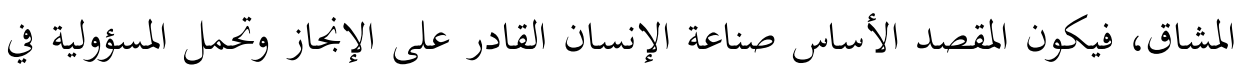

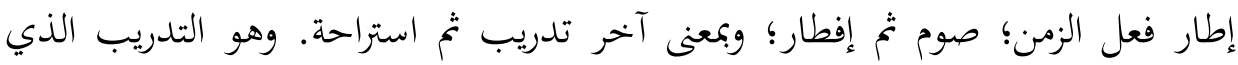

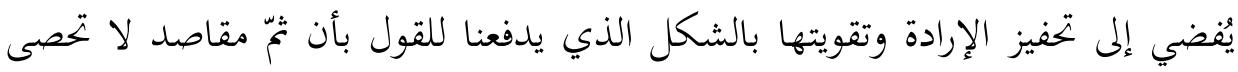
ودروس تكاد تبدأ ولا تنتهي على الصعيد الفردي والاجتماعي، تبدأ بصناعة الفرد

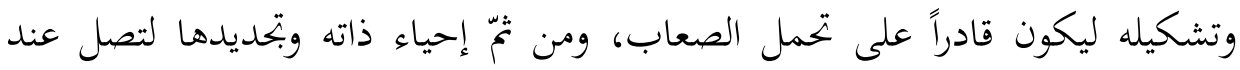

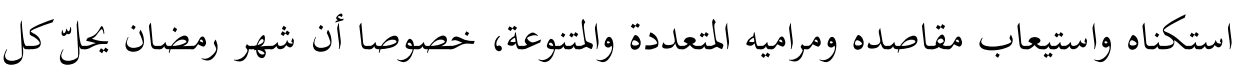

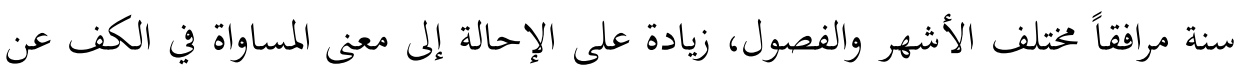
المفطرات بين الفقراء والأغنياء، وكذا الإشارة لوحدة الصائمين في مختلف أصقاع العالم. لمادئ لعل استثمار الزمن وفق مقاربة مقاصدية تنظر إليه بوصفه رأس مال وقيمة مضافة

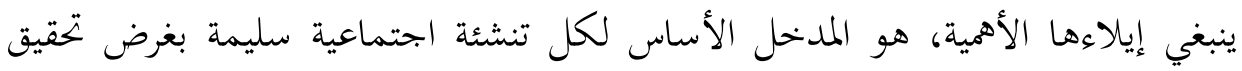

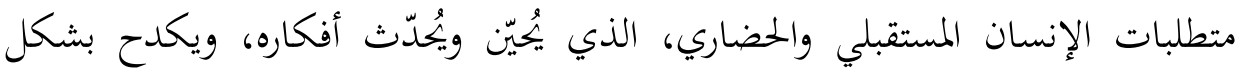

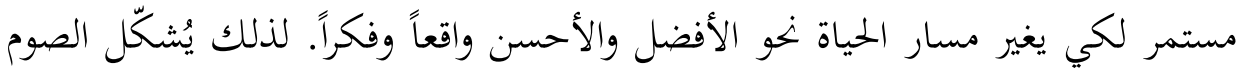




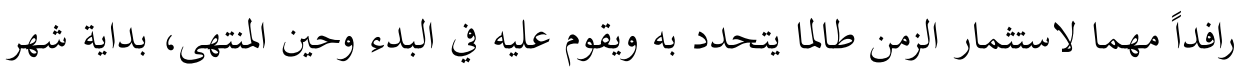

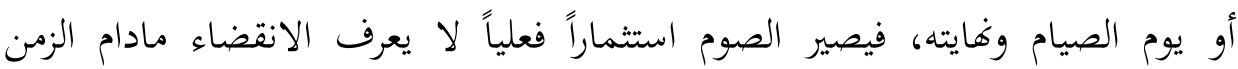

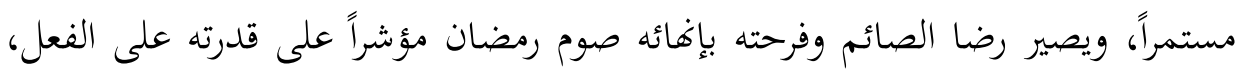

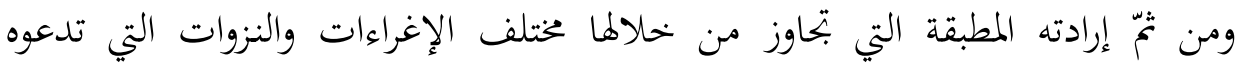

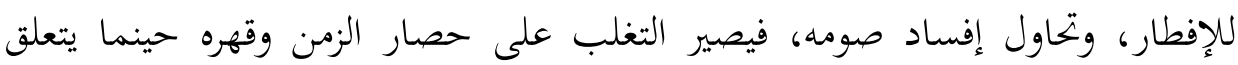

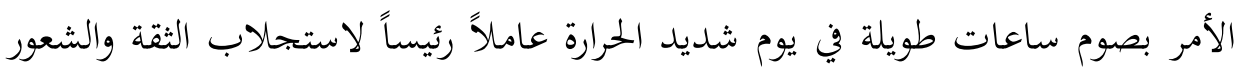

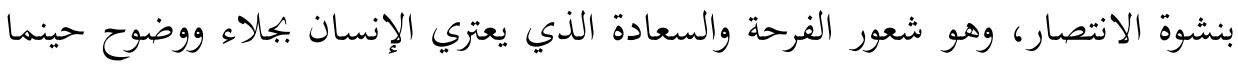

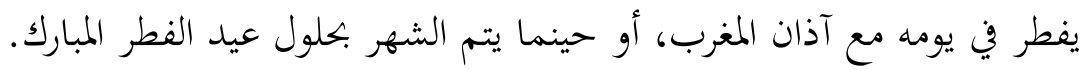

\section{سابعاً: صوم رمضان بين التمثُّل والواقع (تفعيل المقاصد)}

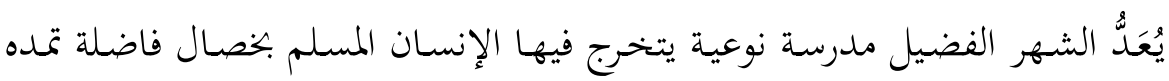

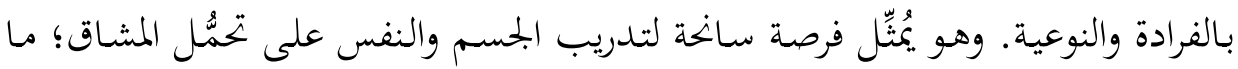

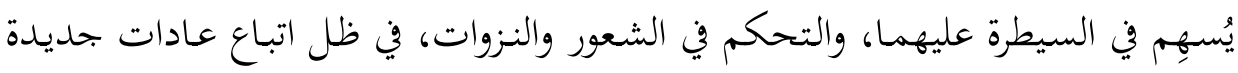

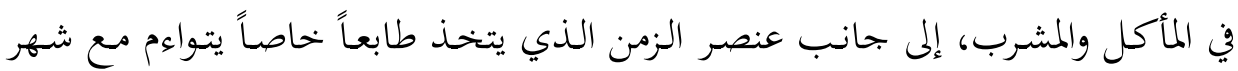

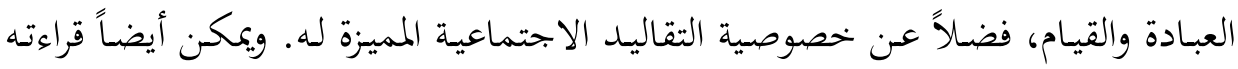

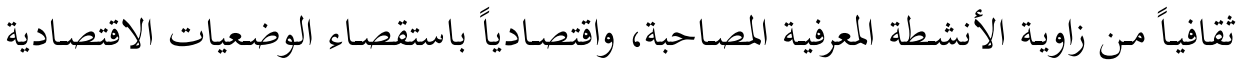
السائدة فيه وتحليلها فردياً واجتماعياً.

وبالرغم من إيجابيات الصيام المتعددة، فإنَّ الإفادة منها تظل مرتبطة بطبيعة الفرد،

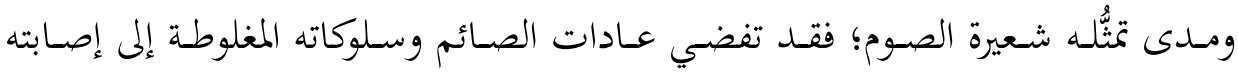

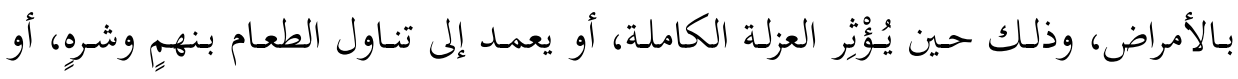
يصر على الصوم من دون مراعاة لحالته الصحية.

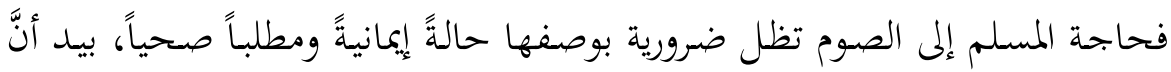

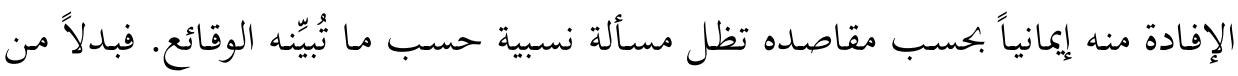

${ }^{29}$ Bickle, Mike. The Reward of Fasting, Experiencing the Power and Affections of God, USA, Forerunner Books, Missouri, 1984, P 118. 
أنْ يكون رمضان شهر التوبة والغفران، أصبح عند الكثيرين فرصة للغنى المادي والاحتكار

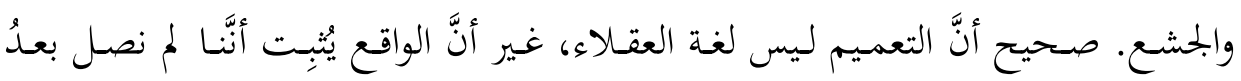

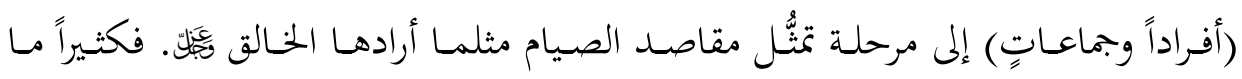

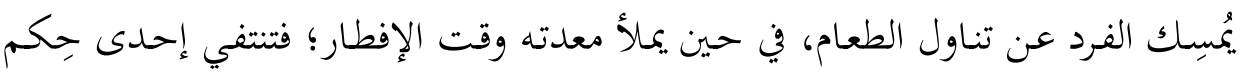

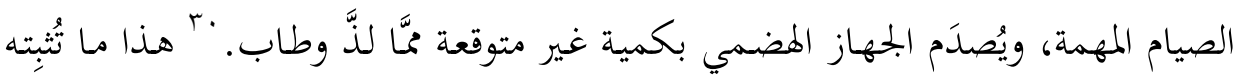

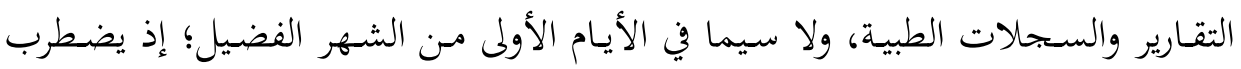

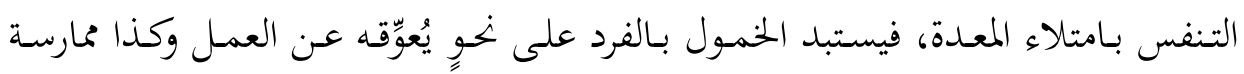

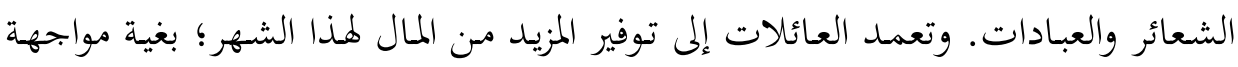

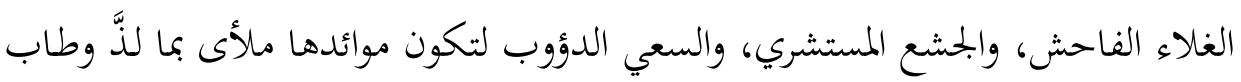
من أصناف الطعام والشراب.

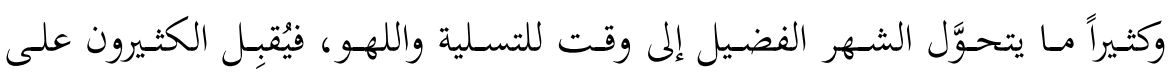

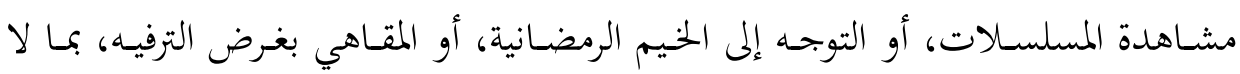

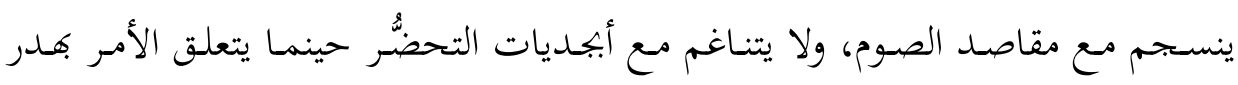
الوقت وتأثير ذلك على إتقان العمل، فضلاً عن مزاحمة الناس بعضهم بعضاً في الأسواق ئساق

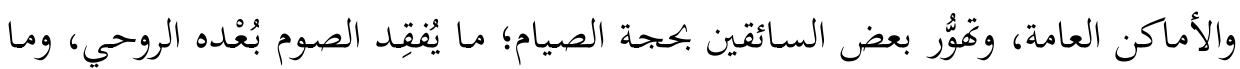
يُمثِّله من شعيرة سماوية ربانية قهدف أساساً إلى تحذيب سلوك الإنسان، وزيادة إيمانه بالتي هي أحسن وصولاً إلى درجة التقوى.

وقد يلتزم بعض الأفراد بأداء الفرائض والعبادات على أحسن وجه طوال أيام الشهر

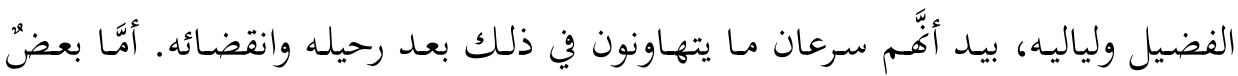

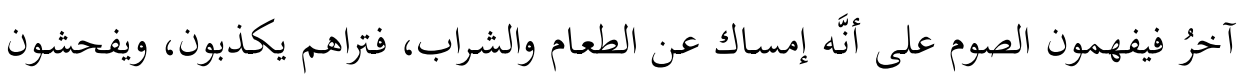
في القول، ويتكلمون في الناس بالسوء، نُمثّلّن النميمة والغيبة في أبلغ صورها.

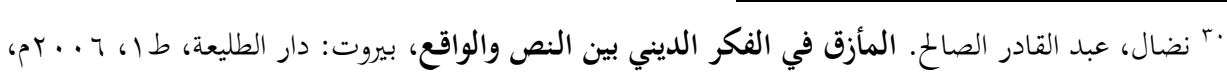
صلr

”r منديب، عبد الغني. الدين والمجتمع: دراسة سوسيولوجية للتدين بالمغرب، بيروت-الدار البيضاء: دار إفريقيا

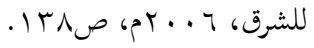


لقد حوَّل الإسـلام بمقاصده الصوم مـن علامـة للحزن، ومظهـر للحـداد، وتنذكار

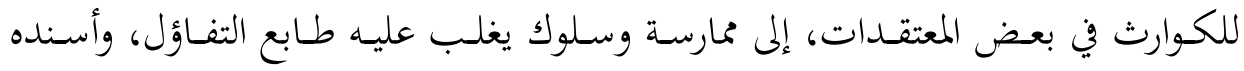

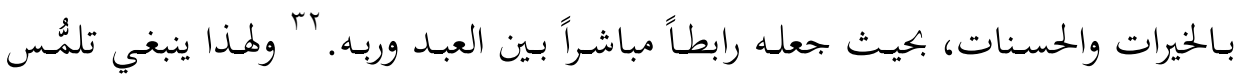

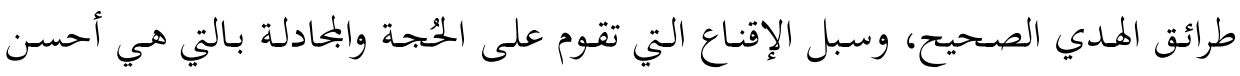

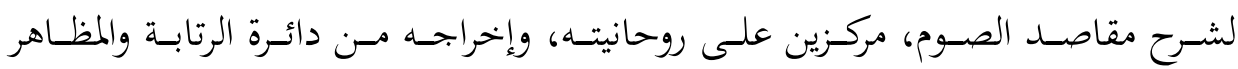

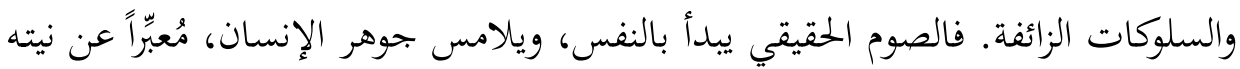

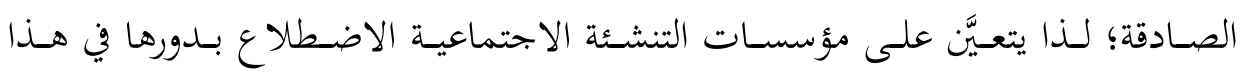

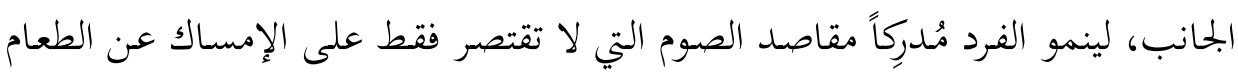

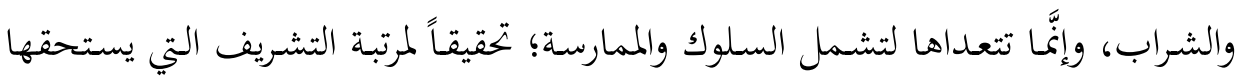
الإنسان بسمته العاقلة.

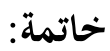

خلص البحتث إلى أنَّ الوسيلة الفضلى لتمثُّل مقاصـد الصوم هي ربطه بالمقاصد

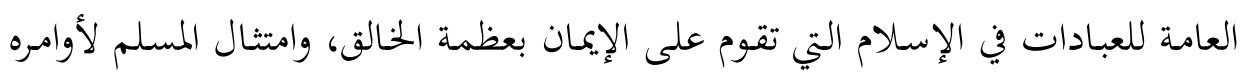

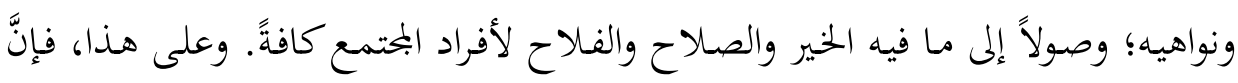

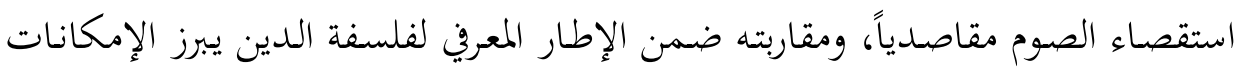

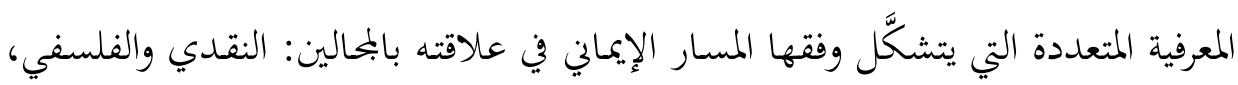

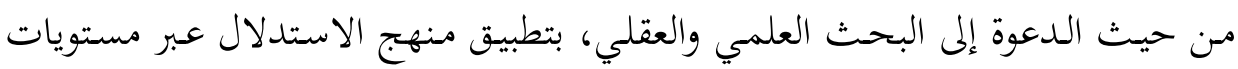
الاستنتاج والاستقراء والمماثلة، بغرض فتح حوار يُمُقِق مراد الفهم والإفهام.

وخلص البحث أيضاً إلى أنَّ قراءة الصوم مقاصدياً تعني بالضرورة البحث في غاياته

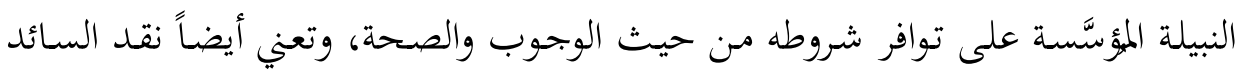

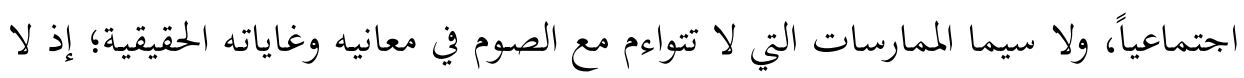
TrT الندوي، الأركان الأربعة: الصلاة، الزكاة، الصوم، والحج في ضوء الكتاب والشُّة ومقارنة مع الديانات

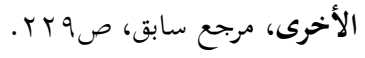


فائدة مـن تأديـة شعيرة دون إدراك مقاصدها ومراميها، لأنَّ المعرفة بالغايات تـدرأ شبهة

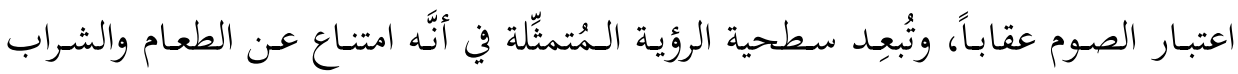

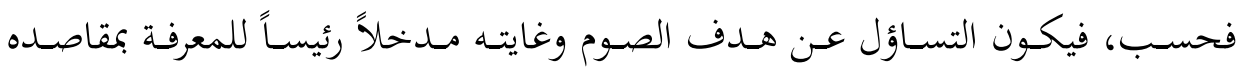

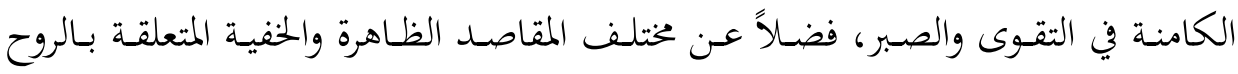

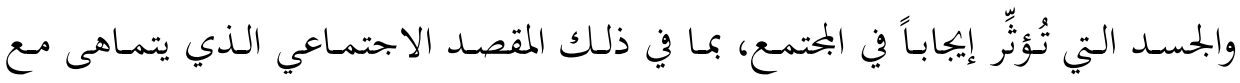

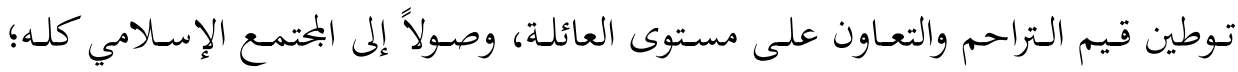

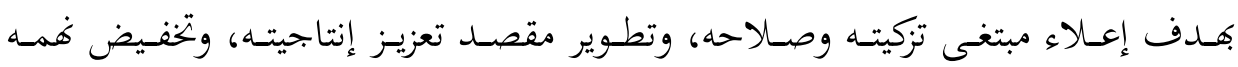

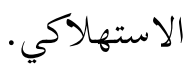

وقد تبيَّن لنا أنَّ محور المقاصد هو الإنسان بوصفه منطلقاً ومقصداً في الوقت نفسه؛

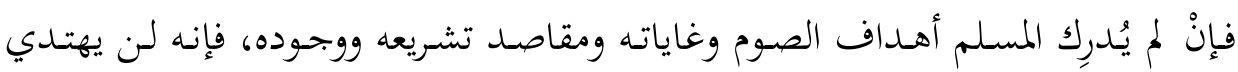

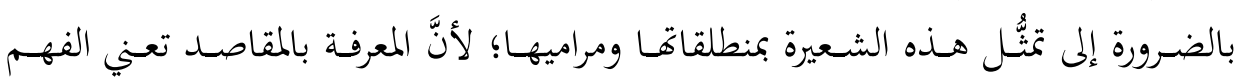

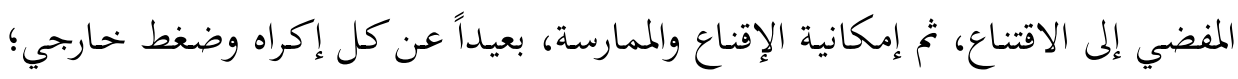
مـا يُسهِم -في هاية المطاف- في بناء الإنسان النوعي الحائز على سمـة التشريف الإلهي

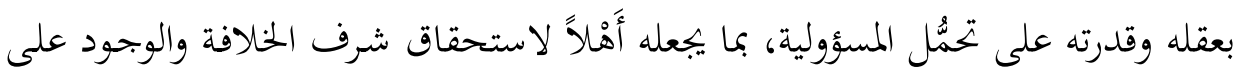

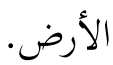

وتأسيسـاً على ذلكَ، يتعـيَّن على المسـلم أنْ يُـدرِب نفسـه ويربيهـا على مواجهـة

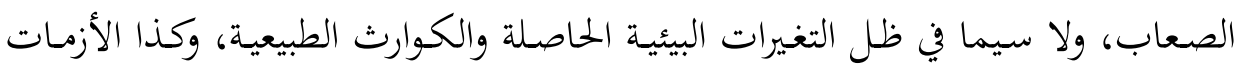

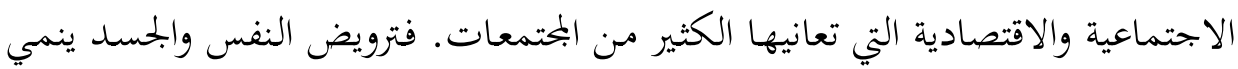

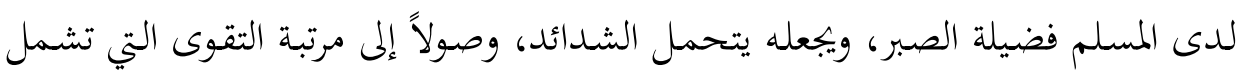

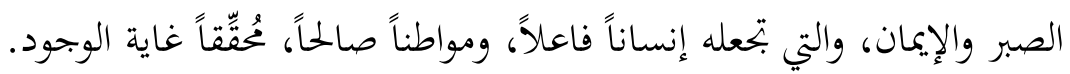

